\title{
INDIVIDUAL DIFFERENCES AND THEIR IMPLICATIONS FOR THEORIES OF LANGUAGE DEVELOPMENT
}

\author{
Elizabeth Bates \\ University of California, San Diego
}

Philip S. Dale

University of Washington

Donna Thal

San Diego State University

Chapter 4 for Paul Fletcher \& Brian MacWhinney (Eds.), Handbook of Child Language.

Oxford: Basil Blackwell, 1995.

\section{Introduction}

Like every other aspect of human development, language development is characterized by variation. Historically this variation has been largely ignored by students of child language, who have concentrated on the remarkable similarities in sequence of development that are usually observed across children acquiring a given. language Individual differences in rate of development and individual differences in learning style have been left to applied practitioners such as speech pathologists and special educators. We believe it is no accident that these professionals, concerned with such important questions as the definition of abnormality, the relationship of language to nonverbal cognition, and the role of environmental variables, have found it essential to focus on variation.

It is our contention that quantitative and qualitative variations within and across components of early language are also relevant, indeed essential, if we want to understand the mechanisms that underlie normal language development. Far from simply reflecting noise in our measuring instruments or variability in low-level aspects of physiological maturation, the variations that we will document here are substantial, stable, and have their own developmental course. Because this variation is substantial, it is critical for defining the boundary between normal and abnormal development; because it is stable, it provides a window onto the correlates and (by inference) the causes of developmental change; and because it has its own developmental course, it can be used to pinpoint critical developmental transitions that form the basis for theories of learning and change.
Although we are well aware of the clinical applications that hinge on an adequate assessment of normal variation (i.e. one cannot define "abnormal" without an adequate definition of "normal"), our primary goal here will be an exploration of the implications of individual differences for theories of normal language. We will concentrate on the early stages of language learning, from the onset of word comprehension (around eight to ten months of age) to the onset of grammar (from 20-36 months). This is the period in which the most dramatic changes in language ability are observed, phenomena which have been amply documented in small- and large-sample studies. It is also a period characterized by dramatic events in postnatal brain development (e.g. synaptogenesis), which means that biological factors may play a particularly important role in those aspects of language that change at the same time (Bates, Thal, and Janowsky, 1992). For these reasons, we stand a good chance of discovering something interesting about the interplay of biology and environment. The chapter is divided into four parts, as follows:

1. Variations in rate within components of early language. In this section we will review evidence for variations in speed of development in word comprehension, word production, first word combinations, and the first stages of grammar. As we shall see, there are enormous individual differences in onset time and rate of growth in each of these components, variations large enough to challenge and constrain the notion of a universal bioprogram (Bickerton, 1984) or a universal maturational timetable 
for early language development (Lenneberg, 1967). Such maturational accounts are insufficient, because the linguistic variations that we observe in perfectly healthy children are so much larger than the variations that are usually observed in other maturational milestones like crawling or walking. At the same time, environmental variables (at least those that have been examined to date) appear to account for only a modest proportion of the variance observed in early comprehension and production of language. At the risk of inviting accusations of radical centrism, we conclude that the variations observed in early language development are so large that they require substantial contributions from both genetic and environmental factors, with special emphasis on their interaction.

2. Dissociations between components of early language. Having demonstrated large-scale variation in rate of development within individual components, we can go on to ask about the degree of association or dissociation in rate of development that is observed between those components. In this section, we will look for evidence of developmental asynchrony between comprehension and production, and between lexical production and grammar. The purpose of this investigation is to locate the seams and joints of the language processor, i.e. components that can develop at different rates because they depend on different cognitive and/or neural mechanisms. Hence this section has implications for the hotly contested issues of modularity and the autonomy or interdependence of linguistic and cognitive systems (Fodor, 1983).

3. Variations in learning style. Continuing our search for the seams and joints of the language processor, we will move on in this section to a brief review of evidence for qualitative variations in learning style (aka. "referential v. expressive style", "nominal v. pronominal style", "analytic v. holistic style"). We end by concluding that stylistic variation is the emergent property of quantitative variations in the informationprocessing mechanisms that all children must have for successful language learning.

4. Atypical populations: variation at the extremes of the normal range. Finally, we will review evidence on the same three themes (rate, dissociations and style) in the early stages of development for several quite different atypical populations: early talkers (a nonclinical but very unusual group), late talkers (many of whom go on to qualify for a diagnosis of specific language impairment), children with focal brain injury (to provide insights into the neural mechanisms that underlie individual differences in early language), and children with contrasting forms of mental retardation (i.e. Williams Syndrome, where language eventually moves ahead of many other cognitive domains; Down Syndrome, where language levels often fall behind mental as well as chronological age). This will be a very brief review of a large topic, but it will help to round out our understanding of the mechanisms involved in early language development, across the period from first words to grammar (Bates, Bretherton and Snyder, 1988). We will conclude that most of the variations observed in atypical populations represent extensions of the variations that are also observed in the normal range.

\section{Variations in Rate}

We will start with variations in rate of development within individual components, a form of variation that is (at least in principle) easy to define and quantify. In fact, this apparently simple form of measurement poses a substantial methodological problem. Estimations of variability, even more than estimations of central tendency, require a substantial sample size. For obvious reasons, this is generally not possible for studies of child language, which are exceptionally time and labor intensive. The great majority of research studies have included fewer than 25 subjects; and many of the most influential have been far smaller, i.e. singlecase studies (e.g. Leopold, 1949) or studies of three or four children (e.g. Bloom, 1970; Brown, 1973). Even studies nominally focussed on individual differences have continued the tradition of small samples or singlecase studies (e.g. Peters, 1983). As illuminating as these studies have been in defining those patterns of individual variation that are possible, the extent and nature of such variation will remain controversial until large samples are available. For this reason, we will concentrate here on a single study with a uniquely large sample of more than 1,800 children: the norming study for the MacArthur Communicative Development Inventories (Fenson, Dale, Reznick, Thal, Bates, Hartung, Pethick, and Reilly, 1993; Bates, Marchman, Thal, Fenson, Dale, Reznick, Reilly, and Hartung, 1994; Marchman and Bates, 1994; Fenson, Bates, Dale, Thal and Reznick, 1994). These results are based on two parental report instruments (CDI:Infants, for children 8-16 months, and CDI:Toddlers, for children 16-30 months) that have been developed over a period of more than 15 years. A variety of studies have demonstrated the reliability and validity of this instrument and its immediate precedessors (Dale, Bates, Reznick, and Morisset, 1989; Dale, 1991; Camaioni, Caselli, Longobardi, and Volterra, 1991). For example, the vocabulary checklists correlate positively and significantly with laboratory assessments (both standard tests and free speech) with coefficients ranging from +0.40 to +0.80 ; the grammatical complexity scale correlates with laboratory measures of Mean Length of Utterance at +0.88 at 20 months and +0.76 at 24 months. In hindsight, this high validity is hardly surprising. Parents have a far larger dataset than researchers or clinicians can ever hope to assemble; it is also far more representative of the child's ability, as it is based on the child's behavior in a wide range of 
situations which call for an equally wide range of language skills.

There are, of course, limitations to the kind of information that can be obtained with parent report. As Bates et al. (1994) acknowledge,

We can say nothing here about phonological development (e.g. segmental v. suprasegmental approaches to the analysis of speech), nor about the frequency with which children use particular vocabulary types (i.e. type/token relations). We cannot distinguish between imitations and spontaneous speech, nor can we specify the range of contexts in which individual lexical items are used (e.g. flexible and productive use v. memorized frames). However, we can provide an exceptionally clear view of developmental changes from 8 to 30 months of age, and we can establish the boundaries of variation........within and across levels of development.

As long we keep these variations firmly in mind, and make no attempts to generalize beyond the factors that can be studied reliably and accurately with parental report, a data base of this kind can be extraordinarily useful.

\section{Methodology}

Parents of 1,803 children between eight and 30 months participated in a norming study for these inventories, conducted in San Diego, Seattle, and New Haven (Fenson et al., 1993). Parents of 673 children between 8-16 months completed the CDI:Infants; parents of another 1,130 children, between 16-30 months, completed the CDI:Toddlers. A minimum of 30 males and 30 females are represented at each age level. Children with serious health problems or extensive exposure to a language other than English were excluded from the study, and are not included in the numbers just listed. The sample includes a wide socioeconomic range, although it is heavily weighted toward families in the middle class (e.g. parents with at least a high school education). For the present discussion, we focus on two core subscales from the CDI:Infants (word comprehension, word production) and three subscales from the CDI:Toddlers (word production, onset of word combinations, and grammatical complexity).

Parents of 500 children in the original sample also completed a second inventory approximately six weeks later. Parents of another 503 children completed a second inventory approximately 6.5 months later. Of this latter group, 62 parents of children in the Infant sample completed the CDI:Infants a second time; parents of 217 children in the Infant sample completed the CDI:Toddlers; and parents of 224 children in the Toddler sample completed the CDI:Toddlers a second time. This information was used to assess the cross-age stability of parental report.

The CDI:Infants includes a 396-item vocabulary checklist organized into 19 semantic categories. Ten of these categories comprise nouns (animal names, vehicles, toys, food and drink, clothing, body parts, furniture and rooms, small household items, outside things and places to go, and people). Additional categories are included for sound effects and animal sounds, games and routines, verbs, adjectives, pronouns, question words, prepositions and locations, quantifiers, and words about time. Parents are asked to indicate which words the child understands (comprehension) and which words the child says and understands (production). Note that we have excluded a third theoretically plausible category, i.e. words that the child says but does not understand. This decision reflects our discovery and acknowledgment of an important limitation of parental report. In earlier versions of the CDI, we asked parents to distinguish between words that the child imitates without comprehension, and words that are produced spontaneously and productively. Our results made it clear that parents find it difficult to make a distinction of this kind; indeed, most parents operate under the assumption that production reflects understanding. We have built that parental assumption into the final version of the CDI, but we realize that there is no way to win on this matter. Degree of productivity is a subtle dimension that must be studied with a different methodology, including in-depth observations of language use and context and detailed interviews with parents that elicit information about the contexts in which words are used (see Snyder, Bates and Bretherton, 1981 and Bates et al., 1988, for results using the interview technique).

The CDI:Toddlers includes a 680-word vocabulary checklist, organized into 22 semantic categories. The larger number of categories on the toddler form is a result of two sections (helping verbs, and connecting words) and the division of outside things and places into separate sections. As vocabulary becomes larger, it is no longer possible for parents to monitor comprehension vocabulary; they are asked only to indicate use (production). The second part of the toddler form is designed to assess morphological and syntactic development. Only two measures from this part will be discussed here. Parents are asked if their child is combining words; they can respond "not yet," "sometimes," and "often." If they respond "sometimes" or "often," they proceed to a set of 37 forced-choice recognition items in which they choose the member of each pair that best reflects their child's current level of language use ("In each of the following pairs, please mark the one that sounds MOST like the way your child talks right now"). The 37 items include contrasts in the use of bound morphemes (e.g. "Daddy car" v. "Daddy's car"), functors (e.g. "Kitty sleeping" v. 
"Kitty is sleeping"), and early-emerging complex sentence forms (e.g. "Baby crying" v. "Baby crying cuz she's sad").

\section{Stability of individual differences}

Before turning to evidence for the substantial variation in rate of development observed in early child language, we should review evidence for the stability/reliability of this variation from the six-month longitudinal data collected in the norming study. To evaluate continuity, we applied a very stringent multiple regression analysis, controlling age (a rough index of maturational status), gender (reflecting a combination of biological and cultural factors), and six family and social class variables (birth order, SES, mother's education, father's education, mother's occupation, and father's occupation), before the Time 1 measure was entered as a predictor of the corresponding Time 2 measure. Five such analyses were performed: Infant-Infant Comprehension; Infant-Infant Production; Infant-Toddler Production; Toddler-Toddler Production; and Toddler-Toddler Sentence Complexity. In every case the earlier measure was a highly significant $(\mathrm{p}<.001)$ predictor of the later measure, accounting for an additional 16.6 percent to 31.1 percent of the variance on the final step. Thus, the individual differences discussed below are unusually robust, compared with other psychometric studies in the same age range (McCall, Eichorn, and Hogarty, 1977). It also follows from these analyses that a substantial portion of the variation described below cannot be explained by such traditional factors as age, gender, and social class.

\section{Vocabulary comprehension}

Figure 4.1 shows the mean developmental function for word comprehension between 8 and 16 months, together with functions that describe children who are 1.28 standard deviations above or below the mean. This contrast (which we will use in most of the graphs that follow) illustrates the developmental zone occupied by approximately 80 percent of the sample (so that the probability of falling outside this region is $\mathrm{p}<.10$ at either tail of the distribution)

For most children, robust evidence of word comprehension first appears between eight and ten months of age. At the eight-month entry point, the mean number of words that parents report in comprehension is 36 , although the median (a more conservative measure) is only 17 . At ten months of age the mean has surged to 67 words, with a median of 41 . By the 16-month exit point for the CDI: Infants scale, children have a mean receptive vocabulary of 191, with a median of 169. These median scores are consistent with other estimates of the onset of word comprehension and its early growth (Benedict, 1979; Rescorla, 1981; Bates et al., 1988). However, the means are relatively high, reflecting much more variability in the onset and rate of receptive vocabulary growth than might have been expected from previous research. For example, the 1.28 standard deviation range at ten months of age goes from a low of zero words to a high of 144 . By 16 months the corresponding range is from 78 to 303 words. An indication of the magnitude of individual differences is the fact that the overall correlation between word comprehension and age is positive and significant $(\mathrm{r}=0.60, \mathrm{p}<0.001)$, but accounts for only 36 percent of the variance. The remainder of the variance must be a combination (exact recipe unknown) of true individual variation and the noise and error of parental report.

Some evidence for the reality of this variation comes from recent electrophysiological studies of comprehension. Mills, Coffey, and Neville (1993) tested a group of ten-month-old children, half of them "early comprehenders" reported to understand at least five to ten words from a short laboratory checklist, and half "early noncomprehenders" reported as not understanding these common words. Event-related brain potentials (ERPs) were recorded while the children listed to familiar and unfamiliar words. Significant differences between familiar and unfamiliar words were observed for children in the "early comprehenders" group, but not for children in the "noncomprehenders" group. Thus the parental report of comprehension was correlated with an electrophysiological measure of recognition. Of course this does not mean that high-performing ten-month-olds understand the meaning of familiar words. The ERP in this experiment is an index of recognition, nothing more. However, it does suggest that parents who report high comprehension are aware of their child's selective sensitivity to speech.

The very high levels of word comprehension reported for children at the upper end of the distribution at eight to ten months may also reflect a much less interesting factor. In particular, some parents may adopt a different and more liberal definition of "understands" than we had in mind, inferring comprehension from nothing more than evidence for high attention and positive affect. There is some evidence that this overestimation may be more characteristic of parents with low education (see Fenson et al., 1994). Nevertheless, taken together, the Mills et al. (1993) electrophysiological data and the cross-age stability cited earlier demonstrate that a high proportion of the variance in early word comprehension is authentic.

\section{Vocabulary production}

Figures 4.2 and 4.3 show the mean developmental function and range of variation (1.28 standard deviations in 
either direction) for word production between eight and 16 months (on the CDI: Infants), and between 16-30 months (on the CDI: Toddlers). The mean and median functions are consistent with previous small-sample studies, showing that expressive language does not get off the ground for most children before 12 months of age. For most children, there is slow growth in vocabulary production from a mean of 1.8 words at eight months (with a median of 0 ), to a mean of ten words at 12 months (with a median of 6), to a mean of 64 words at 16 months (and a median of 40) ${ }^{1}$. By 30 months, the mean score has increased to 534 words, with a median of 573 (notice that the median is now higher than the mean, indicating that the distribution is now skewed by "late talkers" at the low end of the distribution - see section 5). The overall correlation between age and vocabulary is $0.47(\mathrm{p}<0.001)$ for the Infant data, accounting for just 22 percent of the variance. For the Toddler data, the age correlation is 0.68 ( $p<0.001$ ), accounting for 46 percent of the variance. Thus there is a substantial amount of ageindependent variation.

Around these central tendencies, variation in vocabulary production has a complex and interesting time course. There is relatively little individual variance at or before 12 months. The 1.28 standard deviation window at one year of age extends from a low of zero words to a high of 24. However, after 13 months there is a dramatic increase in variability, due primarily to rapid growth in children at the high end of the distribution. At 16 months, for example, children in the top tenth percentile have reported productive vocabularies of at least 154 words, while children in the lowest 10th percentile are still producing no words at all. This highly skewed distribution continues to characterize variation in expressive vocabularies throughout the 16-30-month range, until ceiling effects are operative. For example, at the two-year point (24 months), the mean for reported expressive vocabulary on this measure is 312 words, but the 1.28 standard deviation range goes from a low of 89 to a high of 534 (see also Huttenlocher, Haight, Bryk, Seltzer, and Lyons, 1991).

It seems likely that the nonlinearities in figures 4.2 and 4.3 have something to do with a controversial phenomenon called the "vocabulary burst". Some time during the second year of life, many children experience a marked acceleration in rate of word learning (Nelson, 1973; Dromi, 1987; Gopnik and Meltzoff, 1987; Goldfield, and Reznick, 1990). For most of the children that have been studied to date, the growth curve starts to rise somewhere between 50-100 words. The single best example in the literature comes

\footnotetext{
${ }^{1}$ Although the mean is higher at 16 months for the CDI:Toddlers list than for the same age on the CDI:Infants list, the medians are quite similar: 44 and 40 words, respectively. The skewed nature of the distribution is responsible for the differences in means.
}

from Dromi's detailed and exhaustive longitudinal study of vocabulary development in a single child (see also van Geert, 1991). A number of contrasting proposals have been offered to account for this nonlinear shift. For example, it has been argued that children achieve a sudden insight into the idea that things have names (Dore, 1974), or alternatively, that all objects ought to have a name (Baldwin and Markman, 1989). Others have attributed this shift to a more general change in cognition, including developmental changes in the ability to categorize objects (Gopnik and Meltzoff, 1987) and/or developmental shifts in representational capacity (Shore, 1986; Brownell, 1988). Yet another class of explanations revolve around reorganizations in the phonetic segmentation (Plunkett, 1993) and/or articulatory ability (Menn, 1976). All of these accounts are interesting, but they suffer from two related problems: lack of universality, and absence of an inflection point. Let us address each of these in turn, and then see what we can glean from the large crosssectional data base currently at our disposal.

The first problem with the various explanations of the vocabulary burst cited above revolves around the fact that not all children display a growth spurt of this kind. Reznick and Goldfield, among others, have argued from longitudinal data that the burst is not universal. In some children, vocabulary grows so continuously that it is difficult to identify a single point or narrow region of acceleration (see below). In other cases, vocabulary development is characterized by a series of small bursts, a stairstep pattern that is difficult to reconcile with most single-factor theories of "the burst".

A second problem comes from the discontinuity implied by the word "burst", and by most of the theories that seek to explain accelerations in word learning. Van Geert (1991) and Bates and Carnevale (1993) have noted that individual growth curves described in longitudinal studies of vocabulary development during the second year (see especially Dromi, 1987) are best fit by a smoothly accelerating exponential function, or by related nonlinear functions such as the quadratic or the logistic. By appropriate variation in their parameters, such nonlinear models could lead to growth curves marked by apparently intense bursts, weaker bursts, or no significant acceleration at all. The key insight here is that there is no inflection point in the exponential portion of the socalled vocabulary burst, i.e. no single "take-off point" of the kind assumed by most of the theories cited above. And yet, there does appear to be a region of acceleration during the second year that cries out for explanation.

Because the CDI data base is essentially crosssectional (one cannot construct a growth curve from two points), it cannot provide direct information about the existence, incidence or prevalence of the legendary 
burst. If there are a large number of individual stepwise functions, they are masked by summation across individual children. However, these data can provide two indirect sources of information about the timing and nature of nonlinear changes in rate of development.

First, let us assume that accelerations in rate of development become most evident between 50-100 words. If this is the case, then some children in our sample are on their way to a vocabulary burst between 14-16 months of age (see figure 4.3) — well before the 17-19 month transition predicted by many theories. By the same argument, the data in figure 4.3 suggest that some children in the third year of life are still well below the 50-100-word boundary where the putative burst typically appears. Thus, if a vocabulary burst does occur, its timing is characterized by wide individual variation. For some children, it may occur as early as 14 months, for some as late as 24-26 months.

A second set of facts derives from analyses of stability over time in the MacArthur Norming Study. Reznick and Goldfield (1992) have reported longitudinal data from the 500 parents who completed a second inventory approximately six weeks after the initial questionnaire. Correlations between initial and later scores were computed separately for each age group, based on the child's age at first administration. Correlations for the CDI:Todders exceeded $r=0.90$ at every age. Correlations for the CDI:Infants were in the 0.8-0.9 range for both comprehension and production, with a single exception: at 12 months, the test-retest correlation for infant vocabulary production dropped to $r=0.60$. Analyses of our six-month longitudinal data were consistent with these results, suggesting a discontinuity in individual differences occurring at approximately one year of age. The lower reliability coefficient at 12 months may reflect a general reorganization of infant cognition at the 12-month boundary (see McCall, Eichorn and Hogarty, 1977 for a similar 12-month discontinuity in longitudinal studies using the Bayley Scales of Infant Development). Alternatively, it may reflect a discontinuity in parental perceptions of infant language. That is, the emergence of meaningful speech at 12 months may cause some parents to reevaluate the criteria that they used before this point to define a "real word" (e.g. "I thought he said 'mama' before, but what he is doing now is really different"). If this observation is correct, then the most important discontinuity in early word production is the one that occurs between 12-13 months of age - and not the one that is supposed to occur later in the second year. The putative vocabulary burst from 16-20 months may be the inevitable product of a growth function that is set in motion at the end of the first year, i.e. from 10-12 months.

These statistical observations are consistent with some informal observations of Dale and Thal (personal communication), both of whom have studied early talkers. It is difficult to locate children below the age of 12 months with a demonstrable productive vocabulary of, say, 10 or more words. It is much easier to identify children at 14-16 months with very large vocabularies of 100 words or more. We suspect that there may be a "bottleneck" or "gate" into referential vocabulary which cannot be substantially accelerated. Once through that milestone, however, exceptional ability may lead to a flowering of vocabulary. It is an intriguing, but speculative, hypothesis that this phenomenon may be biologically specified.

\section{Combining words}

For English, with its relatively modest inflectional morphology and general absence of case markings, the initial step in grammatical development for most children is combining words (this generalization is not entirely accurate even for English, and is of course highly inaccurate for languages such as Japanese and Hungarian.) In the MacArthur study, parents were given three options for describing their child's combinatorial language: "not yet," "sometimes," and "often." Parents appeared to interpret these terms quite consistently, even though they were given without precise quantitative specification. Figure 4.4 shows the regular progression in parents' response to this question. There is a gap of approximately three to four months between the two criteria. It might have been expected that "sometimes" would be more easily quantified by parents ("greater than zero") than "often," hence more reliably judged. Contrary to this expectation, the "often" criterion was more highly correlated with both age $(0.58)$ and total vocabulary size $(0.73)$ than was "sometimes" (0.47 and 0.57 for age and vocabulary, respectively). Fenson et al. have suggested that parents choose "often" in response to their children's first use of genuinely productive combinatorial language, in which individual words from a particular syntactic or semantic category may be combined flexibly with a variety of words from one or more other categories to express a consistent semantic relationship. In contrast, the choice of "sometimes" may reflect the appearance of nonproductive or rote combinations that do not reflect a generalized and semantically consistent wordcombining skill. Such rote combinations are likely to have a stronger component of individual stylistic variation than does productive combinatorial language (see below), and are therefore less strongly correlated with other measures of language development.

Whichever criterion is used, it is apparent that there is wide variation in the onset of combinatorial language. At 18 months, approximately 11 percent of parents report that their child is often combining words, and another 46 percent report that their child is sometimes combining words. Although this question was not included in the CDI:Infants, an extrapolation of figure 4.4 suggests that a subset of children are combining words prior to 16 months. We assume that 
these early combinations are formulaic in nature, although there are sporadic reports in the literature of rare but novel word combinations in children as young as 14 months (e.g. the expression "Wadoo baba Water bottle" uttered by a 14-month-old child after throwing a playmate's bottle in a wading pool — Bates et al., 1988). By 25 months, nearly all parents report some combinations, but 19 percent are still not reporting combinations 'often.' Thus the much-used clinical criterion of failure to combine words by age two years (e.g. Rescorla, 1989) corresponds roughly to the lowest 10 percent of the CDI distribution.

\section{Sentence complexity}

Finally, we turn to grammatical development, as indexed by parental response to the 37 forced-choice recognition items. Figure 4.5 illustrates the developmental function and standard deviations for this scale. The 37 items include bound morphemes, functor words, and early-emerging complex sentence forms. The mean developmental function of figure 4.5 is concordant with observational studies of early grammatical development, but there is (once again) substantial variation from the earliest period. Children functioning 1.28 standard deviations above the mean at 16 months are at a level which will not be achieved by children one standard deviation below the mean until 28 months. In other words, there is a full calendar year separating children at the high $\mathrm{v}$. low end of the distribution for sentence complexity.

To clarify the range of variation, and make it more meaningful, we can convert this scale to a more familiar one, namely, Mean Length of Utterance (MLU). MLU is widely used as a measure of early grammatical development, despite a number of limitations (Crystal, 1974; Klee and Fitzgerald, 1985). For purposes of characterizing variation, the two most significant limitations of MLU are the absence of good normative data, and the potential for achieving similar MLU values with quite different syntactic abilities (and conversely, achieving different MLU values with similar syntactic abilities). Here we attempt to characterize variation in MLU with a much larger sample than has been previously available, taking advantage of the high correlation between sentence complexity and MLU. A correlation of 0.84 ( $\mathrm{p}<$ 0.001 ) between sentence complexity and observed MLU was obtained by Dale for a sample of 44 children at 20-24 months (Fenson et al., 1994). Based on this high correlation, a linear regression formula for estimating MLU can be derived from the parent measure: ${ }^{2}$

\footnotetext{
2 To ensure normality and linearity of relationship, both complexity and MLU were log-transformed. Note also that the intercept in this formula is greater than 1.0, due to the fact that a child may receive a complexity score of zero because
}

$\mathrm{MLU}=\mathrm{e}(.174 *(\ln (\mathrm{C}+1))+.7299)-1$.

This estimation formula was then applied to sentence complexity normative data $(n=1,130)$ from the CDI:Toddlers, yielding the developmental function for estimated MLU illustrated in figure 4.6. The mean growth in MLU produced with this method is startlingly close to the estimated norms provided by Miller and Chapman (1981) on the basis of a much smaller sample of 123 children. And, like figures 4.4 and 4.5 , it indicates that normal children of the same chronological age can vary from six months to a year in their "grammatical age".

To summarize so far, substantial variation is observed in early vocabulary comprehension. Equivalent variability does not emerge in vocabulary production until after 12 months, an age which appears to mark a discontinuity. Vocabulary growth is positively accelerated after this point, although it is not yet clear whether this is best characterized as a "burst" or a smoothly accelerating curve. If it is the latter, then it is safe to say that the "true discontinuity" in vocabulary development is the one that starts around 12 months of age. The nonlinearities that are observed after this point represent nothing more (or less) than the predictable course of growth along an exponential function that was set in place around the 12-month mark. There is also a great deal of variability in the onset of word combinations, and the growth of MLU following the transition to grammar. To determine whether this later "burst" in grammar is a true discontinuity, or a continuation of the earlier "burst" in vocabulary, we turn to the analyses of associations and dissociations between components of early language.

\section{Finding the Fault Lines: Dissociations Between Components of Early Language}

In the previous section, we presented evidence showing massive variation in rate of development for healthy, normal children, in every area of early communication and language from 8-30 months of age. The existence of such variation leads to another question: are these variations in rate consistent across all areas of development, or can we document significant dissociations in rate of development between the major components of early language? As we pointed out in the introduction, the existence and nature of dissociations between components of early language is relevant to the vexed issue of modularity.

Fodor (1983) has proposed a distinction between vertical modules that operate on a particular information type and respect the boundaries between

the child is still in the single-word stage, or because the child is combining words, but still producing the less advanced form in each sentence pair. 
domains (e.g. a putative module for face perception), and horizontal modules that cut across information types (e.g. short-term memory, or particular forms of attention). In Fodor's view, the human language faculty is an excellent candidate for vertical modularity, i.e. an innate, encapsulated, special-purpose processor that operates on language and language alone. Fodor makes no claims about further modular sudivisions within this language faculty, although he acknowledges Noam Chomsky's proposal (e.g. Chomsky, 1986 \& 1988) that language itself is made up of distinct subdivisions that fit the criteria for vertical modules (e.g. phonology v. grammar, grammar v. the lexicon - see also Pinker, 1991). In testing for the fault lines of early language development we will examine the case for and against one potential set of horizontal modules (comprehension v. production) and another potential set of vertical modules (grammar v. vocabulary). We note that Fodor might view both of these as instances of vertical modularity, since they deal primarily with the processing of language. However, we will review limited evidence to suggest that the comprehension/ production dissociation implicates abilities outside the boundaries of language proper.

\section{Comprehension v. production}

Every pediatrician has had worried inquiries about children who have barely started to talk, even though they appear to understand much of the speech that is addressed to them. Cases of this sort are also well attested in the child language literature, in virtually every study that has investigated comprehension and production in the same set of children (GoldinMeadow, Seligman, and Gelman, 1976; Bates, Benigni, Bretherton, Camaioni, and Volterra, 1979; Benedict, 1979; Oviatt, 1980; Snyder, Bates, \& Bretherton, 1981; Mills, Coffey, and Neville, 1993 and in press).

Most of these studies have concentrated on comprehension and production of single words, but studies that have investigated comprehension and production of grammatical forms in the same set of children yield a similar conclusion. In a few cases that dissociation actually seems to run in the opposite direction, with children demonstrating poor comprehension of sentence forms that are present in their own spontaneous speech. However, most researchers agree that dissociations of the latter sort reflect cases in which (a) the comprehension test itself involves complex task demands that obscure the child's actual knowledge of grammatical structure (Chapman and Miller, 1975; Crain, 1992), and/or (b) children appear to display production of grammar in advance of comprehension because they are using the grammatical forms in question in unanalyzed formulae that have been acquired through rote memory (Bates et al., 1988). When these confounds are eliminated, then the comprehension/production profiles observed for early grammar match those that have been reported for comprehension and production of single words. That is, some children appear to understand far more than they are able to say (Hirsh-Pasek and Golinkoff, 1991). Furthermore, these profiles appear to be relatively stable over time. In a longitudinal study tracking development from first words to grammar, Bates et al. (1988) report significant correlations between the comprehension/production profiles that children display at the lexical level from 13-20 months, and the comprehension/production profiles that the same children display at the grammatical level at 28 months of age.

The incidence and magnitude of the dissociation between comprehension and production has been demonstrated at the lexical level in two successive large-sample studies within the MacArthur CDI project described above. Figure 4.7 illustrates the relationship between number of words in comprehension (horizontal axis) and number of words in production (vertical axis) for children between eight and sixteen months of age in the CDI norming study. This graph shows a characteristic fan effect, created by a substantial number of children in each sample who seem to understand far more words than they produce including some children who are producing no words at all despite receptive vocabularies of more than 200 words! Hence the comprehension/production dissociation appears to be a robust and pervasive phenomenon in the early stages of language development. But it is a phenomenon that is still in search of an explanation. To find that explanation, we need to consider some of the cognitive and neural correlates of this profile.

First, let us consider the limited evidence that is currently available on the nonlinguistic measures that correlate with comprehension and production, respectively. Since the 1970s, a large number of studies have investigated the cognitive predecessors and correlates of early language milestones, with a particular focus on the correlates of first words and first word combinations in production. Candidates include aspects of tool use and causality (Bates, Camaioni and Volterra, 1975; Bates, Benigni, Bretherton, Camaioni, and Volterra, 1979; Harding and Golinkoff, 1979), categorization (Sugarman, 1983; Gopnik and Meltzoff, 1986, 1987; Mervis and Bertrand, 1993), block construction (Shore, 1986), and symbolic play (Nicolich, 1977; Snyder, 1978; McCune-Nicolich, 1981; McCune-Nicolich and Bruskin, 1982; Shore, O'Connell, and Bates, 1984; Kelly and Dale, 1989; Shore, Bates, Bretherton, Beeghly, and O'Connell, 1990; Rescorla and Goossens, 1992). In most of these studies, no effort was made to parcel out the contributions of comprehension $\mathrm{v}$. production to the observed correlations. However, as we shall see in more detail in section 4 on abnormal variations, comprehension and production map onto different aspects of nonlinguistic development. In particular, when there is a dissociation between these 
two modalities of language, comprehension appears to "win custody" of most of the cognitive correlates of early language. For example, Bates, Thal, Whitesell, Fenson, and Oakes (1989) have shown that variation at 14 months in communicative and symbolic gesture correlates more strongly with lexical comprehension than it does with lexical production. A similar pattern appears in the MacArthur CDI parental report data for children from 8-16 months of age. The finding that nonlinguistic measures correlate better with comprehension than they do with production can be paraphrased as follows:

Most cognitive variables correlate with what the child knows about language (indexed by comprehension), as opposed to what the child does (indexed by production).

A different kind of evidence about the correlates and fellow travelers of comprehension and production comes from recent electrophysiological studies of normally developing children. Mills, Coffey, and Neville (1993, and in press) have examined the eventrelated brain potentials elicited by auditorily presented words in children between 13 and 20 months of age. Although this is clearly a test of receptive processing (i.e. passive reaction to familiar words), Mills et al. report specific patterns of brain activity that distinguish between the child's current level of comprehension (indexed by bilateral waves over posterior cortex) and the same child's current level of production (indexed by waves that are larger over left anterior cortex). Hence, even though these event-related potentials are all elicited in the receptive modality, they suggest that different neural systems mediate comprehension and (latent) production.

To summarize this section, there are robust dissociations between comprehension and production in the early stages of language learning. These dissociations are observed across the transition from first words to grammar, and the profiles of individual children tend to be preserved at both the lexical and the grammatical level. Studies with normally developing children also suggest that comprehension and production draw on different cognitive resources, and are mediated by different neural systems. In particular, rate of progress in comprehension appears to be associated with a wide range of nonlinguistic measures, mediated (at least in the early stages) by bilateral brain mechanisms. By contrast, variations in production have fewer nonlinguistic correlates (when levels of comprehension are controlled), and may involve a special form of mediation by anterior regions of the left hemisphere. We suggest that this dissociation between comprehension and production constitutes a form of horizontal modularity, i.e. a dissociation that cuts across linguistic and (perhaps) nonlinguistic information types.

\section{Grammar v. the lexicon}

In contrast with the comprehension/production profiles described above, any dissociations that we might observe between grammatical and lexical development could be used to argue in favor of vertical modularity, i.e. a dissociation that respects the boundaries between well-specified linguistic domains. However, in our investigation of the relationship between grammar and the lexicon in the first stages of language learning, we have to distiguish between two forms of dissociation: temporal asynchrony within individual children, and dissociations in rate of development across individual children. As we shall see, there is solid evidence for the former but very little evidence for the latter.

The temporal asynchrony between grammatical and lexical development is one of the best-established facts in developmental psycholinguistics. In every language that has been studied to date, children do not combine or inflect words productively until they have passed through a prolonged single-word stage, where content words are used with few (if any) inflectional contrasts. Even in languages such as Turkish and Japanese, in which some inflections appear in the oneword stage, this development occurs after a prolonged noninflected stage. During the one-word stage, there are also significant changes in the composition of the lexicon, changes that signal a shift from reference, to predication, to grammar. Figure 4.8 from Bates et al. (1994) illustrates this change in vocabulary composition from 16-30 months of age, based on cross-sectional results from the MacArthur norming study. In this figure, children are divided by vocabulary level rather than age, as follows: 0-50 words, 51-100 words, 101-200, 201-300, 301-400, 401-500, 501-600, and > 600. Although these 100-word groupings are rather arbitrary, figure 4.8 shows a systematic and elegant relationship between vocabulary size and vocabulary composition. Figure 4.8 illustrates the average proportion of total vocabulary made up of common nouns (i.e. names for common objects), predicates (verbs and adjectives), and function words (pronouns, prepositions, articles, quantifiers, conjunctions, modal and auxiliary verbs) at each vocabulary level. The horizontal lines on the graph represent the total proportion of common nouns, predicates and function words on the list as a whole (i.e. the checklist ceiling for each vocabulary type). If vocabulary development drew randomly (or evenly) from each of these lexical categories, then the average proportion scores at each vocabulary level should follow these horizontal lines. Clearly, this is not the case. Common nouns predominate in the first stages of language learning, reaching a peak around 100 words and then dropping sharply down to the checklist ceiling. Predicates show a slow but steady proportional increase across the entire period of development. Function words show no 
proportional growth at all, averaging approximately 6 percent of total vocabulary until somewhere around the 400-word mark; after that point, function words increase rapidly until they reach the 14 percent checklist ceiling. In other words, each of these vocabulary types shows a different growth function, and each one has its own season.

These temporal asynchronies suggest that different mechanisms may be involved in lexical and grammatical development. But is this necessarily the case? Temporal asynchronies of this kind can also be observed when a single learning device is applied to a complex task with several levels of difficulty. That is, grammatical function words, grammatical inflections and word combinations may come in later than individual content words, for two related reasons:

1. Grammatical forms may come in later than content words because they tend to be short, fast, unstressed, and phonologically reduced. In other words, they are relatively difficult to perceive. In fact, several studies have shown that function words excised from continuous speech are recognized less than 30 percent of the time when they are presented out of context to competent adults (Pickett and Pollack, 1963; Pollack and Pickett, 1963; Goodman, Nusbaum, Lee and Broihier, 1990), compared with recognition rates from 50-80 percent for content words (see also Gerken, 1994; Goodman and Nusbaum, 1994). Hence it appears that adults have to depend on context to assist in the perception of closed-class items. If this is the case, then it suggests the following hypothesis for language development:

Closed-class vocabulary will not be acquired until children have built up a content word lexicon that is large enough to "bootstrap" perception of unstressed grammatical forms.

2. Most function words are relational in nature, i.e. their purpose is to set up a relationship between other items in the sentence. O'Grady (1987) has proposed a formal taxonomy of lexical items into three logical types, based on the number of elements and relationships that must be presupposed for that item to work in its intended fashion. Primaries are elements with a "stand alone" function or meaning. Secondaries are items that depend upon a relation with at least one primary. Tertiaries are items that presuppose or depend upon at least one secondary relationship. Within O'Grady's system, most nouns are primaries, most verbs and adjectives are classified as secondaries, and most (though not all) function words are classified as tertiaries. The developmental results outlined in figure 4.8 are quite consonant with O'Grady's theory: nouns are acquired first because they must be acquired first (although they may coexist with routines like "bye-bye" that also stand alone), verbs and adjectives tend to come in later because they presuppose the prior existence of nouns, and closed-class elements cannot be acquired until some requisite number of primary and secondary elements are in place.

In short, the temporal asynchrony that is invariably observed in the acquisition of lexical and grammatical functions may be an inevitable by-product of phonetic and semantic differences among these linguistic types. Indeed, if proposals by Goodman et al. (1990) and O'Grady (1987) are correct, this temporal asynchrony may reflect a powerful cause-and-effect relationship. To the extent that this is true, we should expect to find robust correlations between lexical and grammatical development across individual children. That is, in fact, exactly what we find (Bates et al., 1988; Bates et al., 1994; Dale, 1991; Marchman and Bates, 1994). In their longitudinal study of 27 children from 10-28 months of age, Bates et al. (1988) report a correlation of +0.83 between vocabulary size at 20 months (determined by parental report) and mean length of utterance at 28 months (based on videotapes of free speech in home and laboratory settings). This correlation falls at the reliability ceiling for MLU (i.e. split-half and test-retest correlations for samples of MLU do not exceed +0.83). Because no measure can correlate any higher with another variable than it correlates with itself (i.e. "Spearman's Law"), we can conclude that the relationship between 20-month vocabulary and 28-month MLU is one that approaches statistical identity.

The developmental nature of this relationship between vocabulary size and grammar is illustrated in figures 4.9 and 4.10 from the MacArthur CDI norming study. Figure 4.9 shows the number of children who are reported by their parents to produce at least some word combinations, as a function of the same eight vocabulary groupings described above (figure 4.8). Figure 4.9 shows that there is a strong correlational relationship between vocabulary size and the appearance of multiword speech. For most children, word combinations start to appear when vocabularies fall between 50 and 200 words. Figure 4.10 displays an equally strong but later-emerging relationship between vocabulary size and sentence complexity (a parent report measure that, as we noted earlier, correlated around +0.84 with mean length of utterance based on laboratory observations). For most children, sentence complexity accelerates markedly (following a smooth exponential function) when total vocabulary exceeds 400 words. Note that there is a significant nonlinear component to the grammar/vocabulary relationship in both these graphs. Marchman and Bates report similar but more specific nonlinear relationships between verb vocabulary (i.e. the number of specific regular and irregular verbs reported on the vocabulary checklist) and the emergence of verb morphology (including correct regulars, correct irregulars, and the appearance of overgeneralizations like "falled"). 
As described in more detail by Plunkett (this volume; see also Plunkett and Marchman, 1991, and 1993; Marchman, 1993) and MacWhinney (this volume; see also MacWhinney 1989 and 1991a, b), these functions are quite similar to the nonlinear "mass action" effects reported in studies of language learning in neural networks. In these connectionist models, the same learning mechanism is responsible for acquisition of vocabulary items and acquisition of the past tense markings for specific present tense forms. In other words, there is no modular distinction between lexical and grammatical learning. Nevertheless, the models display a temporal asynchrony between lexical development and the subsequent emergence of grammatical marking. To illustrate, consider the incremental learning of past-tense marking in a recent simulation by Plunkett and Marchman (1993; cf. Plunkett, this volume). In the early stages of learning, the system appears to learn each mapping from present to past tense by rote, with no generalization to novel lexical forms (i.e. it flunks the wug test) and no overgeneralization errors. As instances of present/pasttense mapping accumulate, some dramatic nonlinear changes are observed: the rate of learning accelerates markedly, overgeneralization errors start to appear, and the system starts to provide a default mapping to novel items (i.e. it passes the wug test). Superficially, the network behaves as though it has switched from one mode of learning (rote) to another (rule). And yet there are no structural discontinuities in the system itself, or in the one-verb-at-a-time nature of the input. Instead, the behavioral discontinuities observed in these simulations result from the operation of a single nonlinear learning device. Simply put, grammatical generalizations (i.e. rulelike behaviors) do not arise until the system has acquired enough instances to support those generalizations. When the requisite number of items has been acquired, dramatic changes can take place, even within a single system.

These neural network simulations provide a possible explanation for the strong nonlinear correlations between lexical and grammatical development observed in human children from 16-30 months of age. Indeed, it could be argued that lexical and grammatical development are paced by the same learning mechanisms - at least within this age range. However, before we accept such a strong conclusion we need to ask whether dissociations between grammar and vocabulary are ever observed. Recall the fan effect observed in figure 4.7, which illustrates the relation between comprehension and production. Figure 4.10 presents comparable information on individual variability in the relationship between vocabulary size and sentence complexity. Note that there is no fan effect at all in figure 4.10, i.e. no children with very large expressive vocabularies but no evidence of grammar. In other words, there are no lexical/ grammatical dissociations in normally developing children from 16-30 months of age. We will return to this point later, in section 4 on variations outside the normal range.

However, this does not mean that grammar and semantics are "the same thing". As Gerken (1994) and O'Grady (1987) have pointed out, function words and content words have different perceptual, semantic and logical properties. Hence they cannot be processed in exactly the same way, even though they may be acquired by the same kind of learning device. In fact, new electrophysiological studies by Mills, Neville and colleagues suggest that content words and function words are mediated by different areas of cortex (Mills, 1993). By the time normally developing children are three years of age, grammatical function words elicit specific patterns of activity over left anterior cortex that are not observed in response to content words (see also Greenfield, 1991). These patterns may be the hallmark of fluent, connected speech, a skill that requires forms of information processing that are not required for the comprehension or production of single words.

To summarize so far, studies of normal children provide robust evidence for a dissociation between comprehension and production. By contrast, there is very little evidence for a dissociation between lexical and grammatical development for children who fall within the normal range. To be sure, temporal asynchronies are reliably observed in the passage from first words to grammar. However, these temporal asynchronies may reflect a powerful cause-and-effect relationship between grammar and the lexicon, reflected in the strong nonlinear correlations illustrated in figures 4.9 and 4.10. We suggest that grammatical development depends upon the establishment of a critical lexical base. Indeed, different grammatical events may each depend upon a different lexical base (e.g. word combinations emerge in the 50-100-word range; verb morphology emerges in the 400-600-word range - see Marchman and Bates, 1994). These massaction effects are consonant with simulations of grammatical learning in neural networks, which suggests in turn that grammatical and lexical development may be achieved with the same kind of learning device (Plunkett, this volume). Nevertheless, there are clearcut semantic and perceptual differences between grammatical and lexical forms, which may require a different mix of processors for rapid and efficient language use.

\section{Individual Differences in Style}

Both the previous sections, which have focused on rate differences among children in specific components of language, and on potential dissociations, or asynchronies, among those components, have implicitly assumed a uniform sequence of acquisition within each of these components. The credibility of this assumption 
is the fruit of several decades of research on child language. It is not the whole story, however. An appreciation of stylistic variation, encompassing differences in sequence and in qualitative aspects of language development, was delayed for many years by a focus on universal sequences of acquisition especially in grammar — as a window onto innate structures and processes, and by an apparently innocent methodological decision to select relatively talkative, intelligible, and nonimitative children for early studies (Goldfield and Snow, 1985). As the domain of child language studies expanded to include semantic and pragmatic development, and a wider range of children were observed, the universal fact of stylistic variation has become obvious.

\section{Three phases in the study of stylistic variation}

At a highly oversimplified level of abstraction, we may distinguish three phases in the study of qualitative variation in early child language. The first might be captured with the phrase "gee whiz." Following Nelson's (1973) seminal monograph on the composition of early vocabulary, a stream of research projects attempted to document variation in specific aspects of language development. Nearly all of them were successful. Comprehensive reviews of this research are available in Wells (1985), Goldfield and Snow (1985), and Bates et al. (1988). Here we note only that whether the components of language are conceived as horizontal or vertical (cf. previous section), variation may observed within each of them. We list just a few examples organized by linguistic content area. Within phonology, differences have been noted in emphasis on segmental v. suprasegmental features, and in the consistency of pronunciation across word tokens. Within semantics, there are differences in the proportions of nouns in early vocabularies, and in the use of semantically empty "dummy" words. Within grammar, there are differences in use of nouns $v$. pronouns in early sentences, and in degree of overgeneralization of morphological rules. And within pragmatics, children differ in their variety of speech acts, and in the balance of declarative and imperative utterances. Alternatively, differences may be organized by processing modules. Children differ in the degree to which comprehension is superior to production, in their rate of imitation and whether it is ahead of or behind spontaneous speech, and whether early utterances are limited to single words or are reproductions of longer phrases and sentences.

The general argument in most of these studies has been to draw inferences from product to process. For example, the higher proportion of nouns in children with referential vocabularies has been interpreted as evidence for an interest in language as a tool for talking about objects and categorizing them, whereas children with expressive vocabularies are assumed to be more socially oriented, and to be acquiring language to talk about themselves and others. Bloom, Lightbown, and Hood's (1975) observation of variability in the use of nouns v. pronouns in early word combinations was interpreted as evidence for two qualitatively distinct strategies, one more "pivot-like" (Braine, 1963) in using all-purpose pronouns in combination with lexical items, the other based on combining content words from large categories. These process differences in turn were often attributed to differences among children specific to the domain of language. For example, Nelson (1981) proposed that children have different hypotheses as to the essential function of language. Bloom et al. (1975) suggested that nominal and pronominal children were distinguished by a concentration on the word-order properties of language or on morphology (i.e. closed-class items), respectively.

A second phase of study of language acquisition styles may be viewed as the "grand synthesis" phase. This phase began with Nelson's $(1973,1981)$ reanalysis of her own data, which showed a substantial correlation between her original classification of children as referential or expressive based on their early vocabularies, and Bloom et al.'s distinction between nominal and pronominal basis of early syntax. This report was followed by a flurry of studies, some databased and some more purely speculative, arguing for a cohesion of the various dimensions of stylistic variation. Table 1, from Bates et al. (1988), represents a synthesis of these arguments, attempting to combine virtually all of the reported dimensions. In this "unitary dimension" or "two-strand" theory of individual differences, infants who are word oriented during the babbling period grow into children with referential vocabularies at the first-word level, and into children who display nominal style in their first word combinations, followed by high rates of morphological overgeneralization during the acquisition of grammar. Conversely, children who are intonation oriented during the babbling period grow into children with expressive vocabularies in the one-word stage, and then show a formulaic, pronominal style in first word combinations, followed by a pattern of grammatical learning characterized by undergeneralization and inconsistent application of rules. At the highest level of generality, these styles have been labelled "analytic" v. "holistic" or "rote," respectively.

Perhaps not surprisingly, given the psychologically loaded terminology of "analytic" v. "rote," the first strand usually included the descriptor "fast learner." And indeed, it also included certain demographic variables - female, firstborn, high SES — assumed to be associated with more rapid language learning. In fact, the primary evidence for this claim was restricted to just two of the aspects of style listed in the table: proportion of nouns, and error rate. Several studies, such as that of Horgan (1981), observed a positive 
relationship between the use of nouns and the overall rate of language development, a finding to which we return below. In the second set of studies, Horgan (1981) and Ramer (1976) demonstrated a positive relationship between rate of errors, including word order errors, and overall rate of development.

As the dimensions of stylistic difference were reduced in number, but broadened in scope, it became increasingly appropriate to look for explanations outside of language proper: the nature of maternal input, the child's temperament, global (IQ) or specific (play, information-processing style, etc.) aspects of cognitive functioning, neurological differences, and others. In addition, new versions of language-based explanations were offered, such as the proposal of Gleitman and Wanner (1982) that learners differ significantly in their emphasis on the open-class lexicon (nouns, verbs, adjectives) and closed-class lexicon (function words). Some of these alternative accounts are summarized in table 2 (adapted from Bates et al., 1988).

It is essential here to distinguish processing mechanisms, such as analysis, or rote memory, from more distal factors, such as gender or maternal input, which may lead to differences in the degree to which children rely on one or the other of these mechanisms. These constitute two qualitatively different levels of explanatory factors. We suggest that it may be a more fruitful research program to characterize first the processing differences, and then seek the more distal explanations. It is too easy to be guided (or misguided!) by implicit or explicit stereotypes about these external factors to inferences about mechanisms which may not be valid, e.g. that higher-SES children have larger vocabularies, that girls have more precise pronunciation, or that the left-hemisphere superiority for analytic processing will lead to a fundamental difference among children in degree of analysis. For this reason, we will have little to say in the present chapter about the exogenous factors that push processing mechanisms apart. Our focus will be on the nature of the mechanisms that underlie a dissociation in styles.

The third phase of the study of stylistic variation may be dubbed "sober reconsideration." It is characterized by a critical examination, on empirical, conceptual, and methodological grounds, of the grand synthesis. Evaluation of a theory of individual differences necessarily requires a substantial number of subjects, measures, and time points. For example, Bloom et al. noted that their two "nominal" children were both girls, whereas the two "pronominal" children were both boys. This is an intriguing observation, but assuming a null hypothesis that any single child has a $50 / 50$ chance of developing either style, there is a 1 in 8 probability that a group of four children would divide in a gender-consistent fashion. A few studies are appearing which at least approximate the requirements above, and the results are generally more complex than the grand synthesis would predict. Bates et al. (1988) followed a group of 27 children through four age levels: $10,13,20$, and 28 months. Correlational and factor analyses based on the full longitudinal data set were most consistent with a model consisting of three language acquisition mechanisms, not two: comprehension, analyzed production, and rote production, with a complex relationship over time between comprehension and analyzed production. For example, MLU at 28 months was predicted by early measures of comprehension and analyzed production, not by MLU at 20 months, which was associated instead with earlier measures of rote production (for further evidence supporting this partitioning, see Shore, 1986; Dixon and Shore, 1992, 1993). In other words, the simple twostrand account (figure 4.11a, from Bates et al., 1988) must give way to a more complex, dynamic account of associations and dissociations over time (figure 4.11b, from Bates et al., 1988).

Even more important than the accumulation of larger data sets on individual variation is the need to embed characterizations of individual variation into a larger model of developmental change. Stylistic variables are not nearly as distinct from developmental ones as the literature would lead one to believe. Children differ in their use of nouns and pronouns in early sentences, as Bloom et al. demonstrated; but children also generally increase their use of pronouns during this period. Children vary in their rate of spontaneous imitation, but there is also an inverted Ushaped developmental trend for imitation, first rising and then declining. And so on down the line. Paradoxically, only if we can separate these two types of variance can we hope to understand their relationship. Otherwise we may only be demonstrating one more time that "good things go together."

\section{The validation of stylistic differences}

What constitutes adequate evidence for the characterization of a dimension of stylistic variation? We suggest there are at least three necessary criteria: The first is the requirement of synchronic generality and discrimination. There are two parts to this requirement, sometimes called convergent and discriminant validity in the psychometric literature. The first is based on the view that a single measure of variability is unlikely to be interpretable or interesting on its own. It might simply be error variance; alternatively it might be genuine, but so limited in scope as to have few implications. Stylistic dimensions which have multiple measures, especially measures based on different types of linguistic performance or content, provide a more substantial basis for interpretation. The second requirement, of discrimination, simply reflects the observation that when everything is changing at the 
same time, correlations are not interesting. Methodologically, this first criterion requires correlations among the proposed system of variables, contrasting with smaller correlations between the stylistic variables and other measures. In practice, the demonstration of these correlations and their interpretation is far more difficult than it sounds. There are three recurring substantial difficulties with the correlational approach. One is that the size of a correlation is not determined solely by the relationship between the underlying constructs, but also by the inherent reliability of the measures. As Spearman first noted, measures cannot correlate more highly with each other than they do with themselves. Many child language measures, especially stylistic ones, have only modest reliabilities, which will depress correlations among them. A second difficulty is that the relationships among stylistic measures may not be linear, as assumed by the test of significance of the ubiquitous Pearson coefficient. The relationship may be nonlinear, e.g. a discontinuity or step function, or even nonmonotonic, as when the extremes of a measure have more in common with each other than with the middle of the distribution. The third difficulty concerns the underlying nature of the variables, which may have different meaning at differing time points. As will be discussed below, the frequency of closed-class words in a child's vocabulary has quite a different meaning at 20 months than at 28 months. Hence, evaluation of a dimension of stylistic variation that includes closedclass word usage must consider carefully the most appropriate age for assessment.

The second criterion for identification of a stylistic dimension is longitudinal continuity. No matter how substantial a dimension of variability may be at a single moment in time, if it has no enduring predictive significance, it is unlikely to play a major role in understanding language development. This is not a requirement for "dimension permanence". Early use of nominals and pronominals in word combinations appears to be a stable characteristic, associated with other aspects of style, though eventually it fades as children become fluent with both approaches to sentence construction. It appears to reflect a genuine difference in first approach to syntax. The three strands identified by Bates et al. (1988) discussed above were supported by synchronic generality and longitudinal continuity. Demonstrating longitudinal continuity is subject to the same difficulties as those listed above under synchronic generality. The third difficulty, the changing meaning of measures, is particularly challenging and important. Kagan (1971) and others have pointed out that there are two types of longitudinal continuity: homotypic continuity (cross-age correlations within the same content domain, such as vocabulary totals) and heterotypic continuity (e.g. correlations between early measures of vocabulary and later measures of grammar). Heterotypic continuity may be more common, and more interesting, theoretically, than homotypic continuity, as it suggests more abstract, underlying explanatory mechanisms. Conversely, what appears to be the same measure at two ages may not be correlated, i.e. a homotypic discontinuity. For example, proximity seeking in a two-year-old is a good measure of attachment to a parent, and is positively correlated with other measures of social and emotional development; proximity seeking in a four-year-old is more likely to be a sign of dependency, with negative correlations to other measures. Thus proximity seeking at the two ages is either uncorrelated or negatively correlated. A similar conclusion holds for closed-class usage: This measure at 20 months correlates significantly and negatively with the "same" measure of closed-class use at 28 months (Bates et al., 1988). Homotypic discontinuity does not eliminate the significance of such measures for understanding individual differences in children; it suggests only that the measures have a qualitatively different relationship to stylistic variation at the two different times.

The third criterion for establishing a dimension of stylistic variation concerns the nature of the measure which is evaluated for synchronic and longitudinal generality. In particular, stylistic variables must be unconfounded with developmental rate, in order to be interpretable. We exemplify both the need for this unconfounding and one approach for doing so with a recent study by Bates et al. (1994). As discussed earlier, a number of studies have reported that referential style, that is, a high proportion of common nouns early in development, is associated with faster rates of development. However, the percentage of nouns in total vocabulary itself shows a monotonic increase longitudinally during the period of acquisition of the first 50 or 100 words. Hence the correlation between rate of development and referential vocabulary observed at a given age style may simply reflect the developmental change in noun use. Those children with larger vocabularies will have a higher proportion of nouns as a consequence of developmental change. As Pine and Lieven (1990) have pointed out, age-based measures and correlations based on them are not appropriate for evaluating stylistic variation.

To address this issue, Bates et al. (1994) used the large norming sample from the MacArthur Communicative Development Inventories discussed earlier in this chapter. Their first goal was to identify developmental changes in vocabulary composition across the 8-30-month period. As noted in section 2, they identified three "waves of reorganization": (1) an initial increase in percent common nouns between 1-100 words, followed by a slow proportional decrease; (2) a slow linear increase in predicates, i.e. verbs and adjectives, with the largest gains occurring between 100-400 words; (3) no proportional change in closedclass vocabulary (pronouns, prepositions, question words, quantifiers, articles, auxiliary verbs, and 
connectives) between 1-400 words, followed by a sharp increase after 400 words. These changes were summarized as "a shift in emphasis from reference, to predication, to grammar."

The second goal of their project was to characterize stylistic variation in vocabulary composition independent of these developmental changes. Figure 4.12 plots the observed changes in percent common nouns as a function of the vocabulary levels adopted in figures 4.8-4.10. In addition to values for children at the mean, figure 4.12 also includes referential-style scores for children who are 1.28 standard deviations above or below the mean at each vocabulary level. It is clear that there is very substantial variation in "nouniness", even when total size is held (approximately) constant. This variation is greatest for children with vocabularies below 50 words, replicating the original observation in Nelson (1973). At this vocabulary level, children who are 1.28 standard deviations above the mean (i.e. "referential style") have vocabularies that comprise more than 58.5 percent common nouns; children who are 1.28 standard deviations below the mean (i.e. "expressive style") have fewer than 18 percent common nouns.

Variation in closed-class vocabulary showed a different pattern, illustrated in figure 4.13. As noted earlier, there is little developmental change in these proportion scores before 400 words, although there is still some variation around the mean (ranging from no closed-class words at all to more than 15 percent). After vocabularies pass the 400 -word point, there are increases in the relative size of the closed class for all children, including those at the low end of the distribution. In other words, everybody has to get around to learning those little words eventually, regardless of style (see also Bloom et al., 1975). Hence developmental and stylistic variation in closed-class proportion scores are confounded after the 400-word point.

With percentile-based measures of vocabulary composition, it was possible for Bates et al. to investigate the correlates of stylistic variation unconfounded with developmental variation, their third goal. Referential vocabulary style for children between 8-16 months with at least 10 words was modestly, but significantly, correlated with age $(0.15)$, gender $(0.11$, girls higher), SES, mother's education (0.18) and father's education (0.19). Note that the positive correlation with age means that children high in referential style are actually older than those with proportionally fewer common nouns, that is, not precocious in overall vocabulary growth. This finding is strikingly confirmed by studies of the longitudinal predictiveness of referential style. Referential style at 8-16 months was not significantly correlated with total vocabulary, percent common nouns, percent closedclass words, or grammatical complexity 6.5 months later. Thus, the result of shifting from age-based raw scores to percentiles based on vocabulary level is to cast substantial doubt on the hypothesis that referential style is a harbinger of language precocity. The lack of correlation, positive or negative, with later closed-class use is also inconsistent with the view that referential children are more likely to display a "telegraphic" style in early word combinations, while expressive children are more likely to adopt a pronominal/holistic style. The modest correlations of referential style with social class and maternal education suggest that environmental factors may contribute some of the variance in early "nouniness."

A second set of analyses investigated the correlates of closed-class proportion scores. As should be clear from figure 4.13, variation in closed-class use appears to change in nature when vocabulary reaches approximately 400 words. Prior to this point there is no increase in closed-class proportion scores as a function of vocabulary size, suggesting that variation is due to stylistic rather than developmental factors; after this point, the same measure is strongly correlated with vocabulary size, suggesting that variation is strongly influenced by developmental status. For this reason, Bates et al. (1994) conducted correlational analyses separately for these two periods. Children were divided into three groups: (1) children who were below that 400 -word level at both time points (i.e. continuity in closed-class style during the nonproductive phase), (2) children who were above 400 words at both ages (i.e. continuity in closed-class development within the productive phase), and (3) the largest and most informative group, children who were below 400 words at Time 1 but above 400 words at Time 2 (to test for continuity or lack thereof around the 400-word border).

For children below the 400-word level at both time periods, early closed-class usage was negatively associated with later vocabulary $(-0.19)$ but positively associated with later closed-class usage (0.46). This suggests some continuity in style within this early period, but it also suggests that the style dimension is unrelated to other aspects of progress in language. For children above the 400-word level at both time periods, closed-class scores were strongly correlated with one another and with progress in vocabulary. This suggests that variance in closed-class use after the 400-word mark is a stable index of productive grammar, and it also shows (from another perspective) that the emergence of productive grammar is paced by lexical growth (see section 2).

A more striking finding comes from the largest group of children, those below 400 words at Time 1 and above 400 words at Time 2 . In this group, there was no relationship between early closed-class use and the emergence of productive grammar. This is an excellent example of homotypic discontinuity, i.e. a measure that looks like the same thing has a very different meaning at Time 1 and Time 2. There was also no continuity 
between early closed-class usage and later vocabulary scores.

So what exactly is the basis of early closed-class use? Bates et al. do report positive correlations below the 400-word point between closed-class proportion scores and age. That is, children who use a relatively high proportion of 'little words' at an early stage of development tend to be somewhat older than children who avoid those words at a comparable vocabulary level. Hence their superior ability to detect and reproduce function words may be due to their more mature memories and/or perceptual abilities. As Bates et al. conclude:

We need not assume that early use of function words is "bad for children." Instead, we suggest that children who are developing slowly (for reasons we do not yet understand) arrive at the "same" stage of lexical development with an information-processing system that is somewhat more mature in other respects from that of younger lexically matched controls." (Bates et al., 1994.)

These longitudinal findings provide still more evidence for the point made earlier, that the same measure may have quite different meaning at different points in development. Closed-class use after 400 words is an excellent indicator of grammatical development, but in early development it reflects a particular stylistic approach.

A supplementary, but potentially very valuable, approach for evaluating dimensions of stylistic variation is the training study. By introducing novel concepts and words in a controlled fashion, we can observe the acquisition of a piece of language in "real time" (Nelson and Bonvillian, 1978), and test our hypotheses concerning processing differences in language acquisition. Bates et al. (1988), for example, introduced a novel object ("fiffin") and action ("glooping") to 20-month-old children at home, and also administered several tests 2-3 days later in the laboratory. Of particular interest was the tendency to imitate the label or the action when it was first presented, and the child's later comprehension in the laboratory. These measures were then related to a twostrand model of individual differences posited for early development: comprehension + analyzed production (something like referential style), and rote production (something like expressive/holistic style). Comprehension of the new label was predicted by other measures of the first strand, e.g. comprehension, whereas imitation was predicted by the second strand. (As Bates et al. (1988) point out, the link to imitation here is limited to imitation of a new label when it is first presented.) Thus the hypothesized differences extended to novel concepts and labels. Interpretation of their results and those of others, such as Nelson, Baker, Denninger, Bonvillian, and Kaplan (1985), is made more problematic because of the curvilinear relationship of imitation to development, observed in many domains. It is likely that the phenomenon of imitation itself would also benefit from an analysis which separates developmental from individual variation. In any case, training studies can provide some of the most direct evidence for both the nature and generality of stylistic dimensions.

\section{Rethinking"analytic" and "holistic"}

The most sweeping characterization of individual differences in early language remains the pair of terms "analytic" v. "holistic." We conclude with a suggestion that the equation of holistic with rote may be a substantial oversimplification. Children who differ along this dimension might better be characterized as differing in the size of the unit they are able or prefer to manage (Peters, 1977). Plunkett (1993) has pointed out that articulatory fluency and articulatory precision may be inversely related, and that a learner who has extracted a longer expression as a chunk may produce it fluently, at the expense of precision. There is an analogy between this inverse variation and the speed-accuracy tradeoffs so often seen in cognitive performance. What appear to be qualitative differences among subjects may simply reflect selection of a different point along the speed-accuracy continuum. A holistic strategy corresponds to emphasizing speed by selecting a larger unit for processing; an analytic strategy corresponds to emphasizing accuracy, by selecting a smaller unit. Such is distinction is consonant with the observation of Vihman (1981) and others that some children utilize a small but consistent repertoire of segmental phonemes in prespeech and early meaningful speech, while others use a larger but less consistent repertoire.

There are, in fact, at least two hypotheses here about the relationship of analytic processes and the preferred size of units, to be distinguished and evaluated in future research. First, it is possible that all children are essentially analytic in their approach to language, but the preferred size of units varies, so some children appear more holistic than others. Alternatively, the dimensions of analysis v. rote processes, and of size of unit, are distinct dimensions of individual differences. Some children have good enough memories, and are sufficiently analytic in approach, that they can pick up larger units and combine them productively, as well as later analyzing them into their subparts. Wong-Fillmore's (1979) wellknown observations of differences among child secondlanguage learners are relevant here. Her most successful learners began by acquiring phrases and sentences of immediate functional use, and then systematically analyzed them into parts for recombination. The two precocious children $\mathrm{M}$ and $\mathrm{S}$, to be discussed in the next section, also exemplify 
highly analytic children with different preferred size of units. Differences in preferred size of units might have continuing consequences for language development. Plunkett suggests that the lack of articulatory precision associated with larger, i.e. formulaic, units might lead to impoverished representations for these longer units, which in turn might hinder the recognition of new linguistic units in the speech signal. He predicts that the vocabulary spurt will be relatively delayed for these children (but cf. previous section on the vocabulary spurt).

To summarize, we have learned some sobering lessons about individual differences in style of language learning, especially with regard to the confound between developmental and stylistic aspects of vocabulary composition (i.e. referential style; closedclass usage). It is increasingly clear that these dimensions of variation cut across different aspects of language processing (i.e. heterotypic continuity), and it is also clear that the "same" measure means different things at different points in time (i.e. homotypic discontinuity). The relevant underlying dimension may involve factors like the size of the unit that children prefer to use at a given point in time, the trade-off between speed and accuracy in linguistic performance, variations in perceptual acuity and/or variations in memory capacity within a given language level. For all these reasons, it is likely that no single measure will suffice if we want to divide children into meaningful groups. It may also be the case that no single language will suffice if we really want to understand the causal mechanisms responsible for stylistic variation. The dimensions of variation that have proven relevant in the acquisition of English might be quite different in another language, e.g. a language like Turkish with a regular and perceptually salient set of inflectional markers (Slobin, 1985a), or a language like Greenlandic Eskimo where a complete sentence may consist of nothing more than a single word with six or eight grammatical inflections (Fortescue and Lennert Olsen, 1992). There is still a great deal to be learned about the nature and meaning of stylistic variation in early language, but we are in a much better position to meet this challenge than we were 20 years ago.

\section{Atypical Children: Variation at the Extremes}

Up to this point, we have focused on variation in normal language development. We have described differences in rate of development, dissociations between comprehension and production (but not between lexical and grammatical aspects of language), and differences in cognitive style that are reflected in language learning in normal children between 8 and 30 months of age. In the final section we turn to studies of a number of atypical populations that have added useful data to the investigation of language acquisition. These include children with delayed onset of expressive vocabulary (late talkers), children with precocious onset of expressive vocabulary (early talkers), children with pre- or perinatal focal brain injury, and children with cognitive deficits resulting from Williams and Down Syndrome. Within each subgroup, our discussion is organized into the same three divisions that we used to describe variation in normal children: variations in rate, dissociations between components, and variations in style. As we shall see, the available data on children at the extremes adds significantly to our understanding of the nature and causes of normal variation.

\section{Late talkers}

Only recently have researchers begun to focus on toddlers with delayed onset of language. Because there is a great deal of variability in early language development, and many of these children will appear normal within a year or so, researchers have been hesitant to call these children language impaired. Thus, they have come to be called "late talkers" by most of the researchers who are studying them (Thal and Bates, 1988a; Caulfield, Fischel, DeBaryshe, and Whitehurst, 1989; Fischel, Whitehurst, Caulfield, and DeBaryshe, 1989; Rescorla and Schwartz, 1990; Paul, 1991; Whitehurst, Fischel, Arnold, and Lonigan, 1992). However, in many samples there is a disturbing continuity in language delay for a substantial proportion of these toddlers (Rescorla and Schwartz, 1990; Scarborough and Dobrich, 1990; Paul, Spangle-Looney, and Dahm, 1991; Thal, Tobias, and Morrison, 1991).

\section{Variations in rate}

By definition, late talkers are delayed in rate of expressive language development. Researchers have shown that rate of development remains delayed in approximately 40 to 50 percent of their late-talking subjects, and that other factors are correlated with continued delay. Paul et al. (1991), for example, reported that children from families with lower socioeconomic status were most likely to remain delayed. Rescorla and Schwartz (1990) noted that those children who were older when initially identified as late talkers, and those with the largest lag in expressive vocabulary were most likely to remain delayed. Fischel, Whitehurst, and Connors (1987) reported that the factors identified by Rescorla and Schwartz were correlated with short-term outcome. However, in a follow-up one year later they reported that all children had caught up in expressive vocabulary (Whitehurst et al., 1992).

Our own studies of three different groups of children also have varying results. In all cases late talkers were defined as children who were in the lowest 10 percent for vocabulary production on the MacArthur 
Communicative Development Inventory (CDI). In our first cohort, 40 percent (four out of ten) of the children were delayed in vocabulary production and MLU one year after being identified (Thal, Marchman, Stiles, Aram, Trauner, Nass, and Bates, 1991). All of those children had been delayed in vocabulary comprehension as well as vocabulary production. Children who had normal comprehension at the first time point had normal production vocabulary and MLU one year later. In the second cohort, nine of 17 children with specific expressive language delay were compared to age- and language-matched controls on MLU and IPSyn (Scarborough, 1990) scores one year later (Thal, Cleveland, and Oroz, in preparation). Late talkers remained delayed in MLU (i.e. they were significantly lower than age-matched controls) but had normal IPSyn scores (i.e. they were significantly higher than language-matched controls and no different from agematched controls). This suggests that their continued delay may have more to do with fluency (i.e. utterance length) than complexity (i.e. diversity of morphosyntactic structures). In a third cohort, children who served in the longitudinal validation of the CDI in the norming study were used (Thal, Bates, and Fenson, 1994). Of 33 toddlers in the lowest 10 percent for vocabulary production who received the CDI again six to eight months later, 19 (or 57 percent) were still delayed in vocabulary production at the second assessment.

Although the data vary to some extent, the majority of the studies indicate continuity in the delayed rate of language development in a large of late talkers over a six-month to two-year period. We are aware of only one study in which the development of children identified as delayed in expressive language at 24 months of age has been followed for a longer period of time (Rescorla, 1993). Data from that study demonstrated normal vocabulary development by age three or four years, but continued delays in subtle aspects of language use for proportion many children through age five. At ages six, seven, and eight most of the specific expressive language-delayed children in this study performed normally on standardized tests of language development. However, they were still significantly different from age-matched controls in a number of areas including verbal short-term memory, sentence formulation, word retrieval, auditory processing of complex information, and elaborated verbal expression. It is also worth noting that although the late talkers did perform in the average range on most of these measures (at or near the 50th percentile), their age-, sex- and SES-matched controls were performing significantly above the national average (in the 70-80th percentile). In short, the jury is still out on the long-range consequences of an initial delay in word production. Some children do qualify for a diagnosis of specific language impairment, but a majority (of still unspecified size) go on to perform within the normal range.

\section{Dissociation between comprehension and production}

The most striking dissociation in our studies of late talkers has been the dissociation between comprehension and production in those late talkers with specific expressive language delay. The mean production vocabulary (based on the CDI) for normal comprehenders in the first group noted above was 23.33 (range 2-64), whereas the mean comprehension vocabulary was 285.8 (range 224-371). In the second cohort the mean for production was 25.1 (1-59) and comprehension was 268.5 (182-405). In both samples comprehension vocabulary (even the lowest end of the range) was well above the average comprehension expected for children with production vocabularies in that range. Hence the late-talker population provides an extreme variant of the comprehension/production dissociations that we described for children in the normal range. The fact that so many of our late talkers do catch up further down the line may be related to their unimpaired receptive language skills. Conversely, their initial delays in expressive language could reflect a temporary bottleneck in processing that can be overcome further down the line.

\section{Dissociation between lexicon and grammar}

Vocabulary and grammar appear to be strongly associated in our studies of late talkers. In the first cohort, subjects with normal comprehension had normal vocabulary production and MLU one year later. Those with delayed comprehension had delayed vocabulary production and MLU one year later. In our second cohort, late talkers were significantly below age-matched controls on MLU, but they performed within the normal range on a measure of syntactic diversity.

Although these results may be typical of late talkers in the earliest stages of language acquisition, we know that some language-impaired children with normal expressive vocabulary have particular difficulty with grammatical morphology. Johnston and Kamhi (1984), for example, found that language-impaired fiveyear-olds had more difficulty with auxiliary, catenative, and infinitive verb structures than MLU-matched controls. Others have noted that many children with specific language impairment are especially weak in use of grammatical morphology, with grammatical morphology lagging behind other areas of language (Johnston and Schery, 1976; Steckol and Leonard, 1979; Kahn and James, 1983; Bliss, 1989; Leonard, Bortolini, Caselli, McGregor, and Sabbadini, 1992). Thus, with prolonged delay it appears that dissociations within language itself can and do develop. It may be 
the case that early grammatical learning is inextricably tied to lexical level, but dissociations develop later at the point where normal children develop a more fluent and automatized ability to use grammar in real time in line with our conclusions for variability in the normal range at the end of section 2 .

\section{Variations in style}

Earlier studies have suggested that the so-called "holistic style" may be more common in children who are developing on a slow schedule (Horgan, 1981; Bates et al., 1988), perhaps because these children have more mature perceptual systems and/or better memory for longer strings of sound compared with younger children at the same level of language development. When vocabulary composition was examined in the cohorts described above, no differences were found between late talkers and vocabulary-matched controls in proportion of open- and/or closed-class words, suggesting that late talkers are not atypical on these dimensions. Hence, the correlation that has been observed between age and "holistic style" may be restricted to children within the normal range of language development.

\section{Early talkers}

\section{Rate of development}

Linguistic precocity has been the focus of only a few studies (Robinson, Dale, and Landesman, 1990; CrainThoreson and Dale, 1992; Dale, Robinson and CrainThoreson, 1992; Thal and Bates, 1988b; Thal, Bates, and Zappia, in preparation). In our studies, we have defined early talkers as children between the ages of 11 and 21 months of age who are in the top ten percent for vocabulary production for their age on the CDI. By definition, they are ahead of their peers, demonstrating considerable variability in the rate of language development in this early period.

We know relatively little about the long-term stability of early precocity in language. However, at least one study suggests that early talkers tend to stay ahead of their peers. Robinson, Dale, and Landesman (1990) identified children as precocious at 20 months on the basis of vocabulary, MLU, or verbal reasoning (language items on the Bayley Scales of Infant Development) at a level two standard deviations above the mean. Their precocity was maintained for the five years of the project. For example, at 24 months the mean MLU for this group was 3.14, equivalent to that of average children at 36 months; at 30 months the mean PPVT-R vocabulary age equivalent was 42.6 months; and at age $6^{1 / 2}$, their Stanford-Binet IV Vocabulary age equivalent was nine years, ten months. Each of these scores is approximately two standard deviations above the mean, suggesting that early talkers maintain a significant advantage throughout early childhood.

\section{Dissociations between comprehension and production}

Many of these early talkers appear to be equally precocious in comprehension and production. However, as in the late talkers described above, there are also a number of children who display a dissociation between comprehension and production. In this case, the dissociation takes a different form: Production does not exceed comprehension, but the disparity between receptive and expressive vocabulary displayed by most normal children (and adults) is markedly reduced. In essence, these early talkers might be described as "saying everything they know". As a result they are normal in comprehension (i.e. around the 50th percentile for their age) but abnormally high in production (in the upper 10th percentile for their age). Hence there is strong evidence for a dissociation between comprehension and production at both extremes of the normal distribution.

\section{Dissociations between lexicon and grammar}

Some interesting relationships between grammar and the lexicon have been observed in some of our early talkers. We have studied four of the children with extremely precocious language development in some detail (Thal and Bates, 1988b; Thal, Bates, and Zappia, in preparation). In two of these children, grammar did appear to lag behind lexicon, suggesting some degree of dissociation, at least in extreme cases. However, detailed examination of the data reveals an unexpected association between vocabulary development and inflectional morphology in these two single-word-stage children. Table 3 (from Thal, Bates, and Zappia, in preparation) provides examples of the utterances produced by two of the children who form a contrasting pair: $S$ (17 months old with an expressive vocabulary of 603 words in the CDI) and M (21 months old with an expressive vocabulary of 696 words on the CDI). With an MLU of 2.13, S demonstrates the correlation between grammar and vocabulary that we have come to expect. $\mathrm{M}$, on the other hand, has just begun to combine words (MLU 1.12). At first glance it appears that grammar and vocabulary are dissociated in this child. However, $M$ does produce contrasting grammatical inflections in her single-word speech. This is a very odd phenomenon for children acquiring English, but typical of children acquiring a highly inflected language such as Turkish (Slobin, 1985a). In fact, the amount and type of grammatical morphology observed in M's speech falls well within the range that we would expect for children with more than 500 words (Marchman and Bates, 1994 ). Thus, the seeming dissociation between lexicon and grammar does not 
exist. The difference between these children must be sought elsewhere, which brings us to the next point.

\section{Variations in style}

In the early-talker group identified within the CDI norming study, we found the same range of variation in referential and/or closed-class style evidenced by children further down in the distribution. This mirrors our results (or lack thereof) for late talkers, suggesting that vocabulary style is not uniquely associated with slow or fast rates of language learning.

However, we did find some interesting evidence for stylistic variation in the case studies of very early talkers described above. Whereas $M$ produced carefully articulated single words, $\mathrm{S}$ was observed to use longer utterances that often appeared formulaic in nature. Her parents indicated that she could remember and produce a number of songs and idiomatic expressions (e.g. "No way, José," or "You little monkey!"). An examination of the sample utterances for $\mathrm{S}$ in table 3 supports this idea. She appears to make use of partially analyzed formulae and "frame-slot" structures in her spontaneous speech (e.g. "Where went?"). In fact, to the surprise and amusement of her mother and the experimenter, $\mathrm{S}$ produced a novel juxtaposition of two established formulae during one of the experimental sessions: "No way, you monkey!" Thal et al. tentatively conclude that the apparent dissociation between grammar and lexicon illustrated by $\mathrm{M}$ and $\mathrm{S}$ actually reflects a style dimension based on the length of the unit that can be retained in memory. Both $\mathrm{M}$ and $\mathrm{S}$ appear to produce analyzed utterances, and both seem to use a slot-filler approach to combining words. Examples of $\mathrm{S}$ 's formulaic combinations were noted above. M's few two-word utterances were typical pivot-style utterances made with two pronouns (see table 3) including "hold it", "keep it", "pour it", and "hide it". What was different between the two children was not so much analytic versus holistic processing but, rather, the size of the units which they were able to combine.

\section{Children with focal brain injury}

For a number of years, we have studied the first stages of language development in children with unilateral damage to the right or left hemisphere, injuries that were acquired prenatally or before 6 months of age (i.e. before the onset of meaningful speech). It has been known for some time that children with this etiology go on (more often than not) to achieve normal or nearnormal levels of language ability, despite damage to areas that often result in irreversible aphasia when they occur in an adult (Lenneberg, 1967; Hecaen, 1976; Rasmussen and Milner, 1977; Woods and Teuber, 1978). Hence this group of children provides compelling evidence for the plasticity of neural organization for language in our species. However, this does not mean that the newborn brain is equipotential for language (for reviews, see Satz, Strauss and Whitaker, 1990; Stiles and Thal, 1993; Aram and Eisenberg, this volume). Current evidence suggests a compromise between two theoretical extremes (i.e. irreversible determinism v. total equipotentiality). There are initial biases, which affect the timing and nature of early language, but eventually most of these children find alternative modes of behavioral and/or neural organization that are sufficient to sustain adequate (if not optimal) language development.

In this section, we will review evidence on the early stages of language in children with focal brain injury with two purposes in mind: (1) to uncover further evidence for variations in rate and style and dissociations between components, at the extremes of normal development, and (2) to provide some insights into the neural bases of the patterns that have been observed in other populations.

\section{Rate of development}

As a group, children with focal brain injury are delayed in phonology (Marchman, Miller, and Bates, 1991), and in lexical development (Thal et al., 1991) and MLU (research in progress). These group delays have been found to continue through 44 months of age (our most recent data point). However, there are exceptions among individual children, including some who fall within the normal range from the very beginning. In the largest sample that we have studied to date, 38 children between 16-31 months of age have been assessed with the vocabulary scale of the CDI: Toddlers. For the group as a whole, including those with left- and right-hemisphere damage, 16 out of 38 children (approximately one third of the sample) have vocabulary scores in the bottom 10th percentile. Although this is far more than we would expect by chance $(\mathrm{p}<0.001)$, it also means that most children with focal brain injury fail to meet the criterion used to define late talkers. When attention is restricted only to the children with left-hemisphere damage, 13 out of 25 children (one half of the sample) fall in the bottom 10th percentile. Obviously left-hemisphere damage is a serious risk factor for early language delay, but it is also true that half of even this 'high risk' sample falls within the normal range, including a substantial number of children with scores well above the median.

We are now trying to determine those sites within the left hemisphere that are most often associated with a serious initial language delay, to determine whether and to what extent the "risk sites" map onto findings from brain-behavior mapping in adult aphasics. So far it is clear that these results will be approximate at best. Some sites may be more important than others (e.g. sites surrounding Broca's and Wernicke's areas). However, we have seen individual cases of children with injuries that involve all of the tissue in and around the classical language areas, who nevertheless display 
normal levels of language comprehension and production (see also Dall'Oglio, Bates, Volterra, Di Capua, and Pezzini, 1992; Feldman, Holland, Kemp, and Janosky, 1994; Vargha-Khadem, Isaacs, Van der Werf, Robb, and Wilson, 1992). These findings on the earliest stages of development in children with focal brain injury fits with a well-established finding on the long-term sequelae in this population: more often than not, these children go on to develop language skills that are well within the normal range, testimony to the extraordinary plasticity of the human brain for its most important cognitive skill.

\section{Dissociations between comprehension and production}

Within the focal lesion population, we find some of the same strong dissociations between comprehension and production reported for the late-talker sample. At the same time, we also find children who are impaired in both modalities, and children who appear to have escaped unimpaired in both receptive and expressive language.

One of the first questions that we have asked of this population pertains to the neural sites associated with deficits in comprehension $v$. production. The answers to date are mixed (Thal et al., 1991; Wulfeck, Trauner, and Tallal, 1991), but they do suggest some differentiation in the neural mechanisms that underlie development in these two modalities. Comprehension deficits occur with damage to either hemisphere, and are (if anything) somewhat more common in children with unilateral right-hemisphere damage. Hence, we tentatively conclude that early comprehension is a "whole-brain activity", i.e. a bilaterally distributed process that may require more right-hemisphere mediation during the early stages of learning than we see in adults with equivalent forms of brain injury. This is, in fact, quite compatible with the electrophysioogical studies of comprehension and production in normal children that we reported in section 2 (Mills et al., 1993, and in press).

Production deficits do appear to be somewhat more likely with damage to the left hemisphere, although the intrahemispheric sites associated with initial delays are variable from one study to another. In the study by Thal et al, delays in expressive vocabulary were equally likely between 12-16 months with left- or righthemisphere damage, and with damage to both anterior and posterior sites on the left. In other words, brain damage is certainly not a good thing to have, and it is hard to get expressive language off the ground with any form of cortical or subcortical damage. By contrast, between 16-36 months, there was a clear association between continued expressive delays and damage to left-hemisphere sites. In the Thal et al. sample, these delays in recovery of expressive language were greater in children with left posterior damage - a peculiar reversal of the usual story for adult aphasics (where damage to frontal sites around Broca's area tends to result in nonfluent aphasia). However, in our more recent studies with an expanded sample, delays in recovery from expressive deficits are associated with specific sites in both the anterior and posterior quadrants of the left hemisphere.

These results are complicated by a number of factors, including (a) the absence of a solid data base on normal brain development to anchor analyses of damage to specific lesion sites (see Bates et al., 1992, for a discussion of this point), and (b) confounding factors like seizure activity and seizure medications that plague research on children with focal brain injury. For the moment, we must be content with only one tentative conclusion: Dissociations between comprehension and production do occur in the focal lesion sample, and they appear to be associated with different patterns of focal brain injury. However, the brain-behavior correlations observed in early language development do not map consistently onto the correlations that are observed in adults with analogous lesions.

\section{Dissociations between lexicon and grammar}

In contrast with the strong dissociations between comprehension and production that appear in the focal lesion population, we find (once again) virtually no evidence for a dissociation between grammar and the lexicon - at least not within the period from 20-36 months when the foundations of grammar are laid down. Indeed, within our latest sample of toddlers with focal brain injury, the correlation between vocabulary and grammar scores falls between $+.70-+.92$, depending on the subset of children who are included or excluded from the sample. Thus we may conclude that early grammatical development is lexically driven in this population as well. However, we leave open the possibility that a dissociation may appear at later stages of development, when grammar must become a fluent and automatized skill.

\section{Variations in style}

One of the first questions that we are often asked when we lecture on individual variations in style revolves around the potential neural bases of the analytic/holistic contrast. For example, it has been argued that the right hemisphere of the normal adult brain plays an important role in the integration of perceptual information (including but not restricted to visual-spatial patterns) into a global configuration, while the left hemisphere plays a more important role in the extraction of perceptual detail (Robertson and Delis, 1986; Lamb, Robertson, and Knight, 1990; Dukette and Stiles, 1991). By analogy to this analytic/holistic division in perceptual analysis, it has been suggested to us that children who evidence a holistic approach to language may make greater use of right-hemisphere processes, 
while children who adopt an analytic style rely to a greater extent on left-hemisphere processes.

A different neural basis for stylistic variation has been suggested for children with left-hemisphere damage. In particular, it has been pointed out that children at the extreme analytic end of the normal distribution produce telegraphic speech with a high proportion of content words and very few function words (e.g. "Mommy sock") — very much like the speech that is characteristic of adult patients with Broca's aphasia. By the same token, children at the extreme holistic end of the normal distribution tend to produce utterances with a relatively high ratio of function words to content words (e.g. "I wan' dat") very much like the speech that is characteristic of adult patients with Wernicke's aphasia. To the extent that (a) Broca's aphasia is correlated with left frontal injury, and (b) Wernicke's aphasia is correlated with left posterior injury, it has been proposed that the analytic/holistic dimension in early language learning could reflect differential use or rate of maturation in anterior $v$. posterior regions of the left hemisphere, with "little words" handled by the regions around Broca's area and content words mediated by left posterior cortex.

Our evidence on this point is meager and inconclusive on both these points, but to the extent that it can be used at all, it suggests exactly the opposite conclusion on both counts. In general, we find the same mix of vocabulary composition scores in our focal lesion population that we find in the normal range, and in both our late-talker and early-talker groups. Nor do we find a strong association between language style and lesion type, organized by side (left v. right) or site (left anterior v. left posterior). However, the study by Thal et al. found significantly less use of closed-class morphemes in children with injuries involving left posterior cortex - in direct contradiction to both the interhemispheric hypothesis (right hemisphere = holistic; left hemisphere $=$ analytic) and the intrahemispheric hypothesis (left anterior = function words; left posterior $=$ content words). A more definitive answer regarding the cortical basis of analytic v. holistic style will await studies that use a broader range of measures, including laboratory analyses of imitativeness, phonological precision, and speech rate.

\section{Williams Syndrome and Down Syndrome}

A final source of information on the extremes of variation comes from children with two dramatically different forms of mental retardation, Williams Syndrome and Down Syndrome. Children with Down Syndrome are markedly delayed in the acquisition of language, but more importantly, their language abilities at virtually every stage (including the adult steady state) fall below the levels that we would expect based upon their mental age (Miller, 1987; Bellugi, Marks, Bihrle, and Sabo, 1988; Bellugi, Sabo, and Vaid, 1988; Miller,
1988; Bellugi, Bihrle, Jernigan, Trauner, and Doherty, 1990; Jernigan and Bellugi, 1990; Reilly, Klima, and Bellugi, 1991; Bellugi, Bihrle, Neville, Jernigan, and Doherty, 1992; Wang, Doherty, Hesselink, and Bellugi, 1992; Wang, Hesselink, Jernigan, Doherty, and Bellugi, 1992; Mervis and Bertrand, 1993; Bellugi, Wang, and Jernigan, 1994; Miller, in press a \& b). Furthermore, they appear to be especially impaired in the use of bound and free grammatical morphemes, constituting a form of congenital agrammatism that is even more severe than the selective impairments in grammatical morphology reported for children with Specific Language Impairment (see above). By contrast, older children and adults with Williams Syndrome display levels of linguistic knowledge and language use that are surprisingly good when they are compared with the low levels of performance that the same individuals show on most measures of visual-spatial cognition, problemsolving and reasoning (Bellugi, Delis and Marks, 1989; Bellugi et al., 1992; Bihrle, Karmiloff-Smith, and Grant, 1993; Carey, Johnson, and Levine, 1993; Mervis and Bertrand, 1993). to here

Before we go into details on the early stages of language learning in these two groups, we should point out that older children and adults with Williams Syndrome cannot be characterized as "language savants", where savants are defined as retarded individuals who show skills far above normal in a single domain. Indeed, those studies that have used normal controls have shown that the linguistic performance of Williams subjects is invariably below their chronological age - which is, of course, not surprising for subjects with an IQ score around 50. When they are compared with younger normals matched for mental age, the picture is mixed: they perform above mental-age controls on some measures (e.g. the Peabody Picture Vocabulary Test, word fluency, and a number of measures of grammar) while they look very much like mental-age controls on others (e.g. the Wisc R). The excitement that research on Williams Syndrome has engendered in recent years hinges not on their absolute levels of performance, but on the striking profiles of sparing, deviance and delay that they display across different linguistic and nonlinguistic tasks - a profile that challenges many existing theories of the relationship between language and cognition. On some linguistic measures their performance is not only superior to mental-age controls, but qualitatively different from normals of any age. For example, on word fluency tasks (e.g. "Name all the animals you can think of") they tend to produce lowfrequency items like "ibex" and "brontosaurus" that are never produced by normals or by other individuals with mental retardation. Even more compelling evidence for qualitative variation comes from a story-telling task (Reilly, Klima, and Bellugi, 1991), where Williams Syndrome children and adolescents were compared with normal controls and with IQ-matched subjects 
with Down Syndrome. In retelling the same story to the same audience, normal children and Down Syndrome individuals tend to produce succinct stories with relatively flat affect, stories that get shorter and less interesting with every retelling. By contrast, the Williams Syndrome subjects produce novel, colorful, and emotional descriptions on every trial, with no loss of enthusiasm. Aside from their command of the grammar, their stories abound with rich prosody and "audience hookers" like "You know what?", or "And then guess what happened!". This level and style of performance has not been observed in any other normal or clinical group. The peculiar patterns of sparing and impairment that are observed within the language domain in Williams Syndrome are complemented by equally interesting patterns of sparing and impairment outside of language. For example, although they show severe impairments on most visual-spatial tasks, they are remarkably good at face recognition (Bellugi, Wang and Jernigan, 1994; see also Bertrand, Mervis, Rice and Adamson, 1993), surpassing their age-matched controls on some measures. And although they perform poorly on virtually all reasoning and problem-solving tasks, they are far less impaired on so-called "theory of mind" tasks that require an ability to reason about the intentions and plans of other human beings (KarmiloffSmith and Grant, 1993).

Taken together, these contrasts between Down Syndrome and Williams Syndrome provide an important challenge to interactive theories of language and cognition, and appear at first glance to provide considerable support for the autonomy of language from other cognitive systems (Karmiloff-Smith, 1992; Bellugi, Wang and Jernigan, 1994). However, when we compare the early stages of language development in these two clinical groups, a somewhat more subtle picture emerges.

Rate of development. A number of studies have begun to explore the early stages of language development in children with Williams syndrome. In every case these children are significantly delayed and the developmental period is prolonged (Thal, Bates and Bellugi, 1989; Mervis and Bertrand, 1993). In other words, despite their ultimate proficiency with language, children with Williams Syndrome are late talkers. This has become exceedingly clear in a recent study by Bellugi, Bates and colleagues (research in progress), who have used the MacArthur CDI to obtain early language data from more than 130 children with Williams and Down Syndrome, between one and six years of age.

In the period of development covered by the CDI: Infants (equivalent to normal children between 8-16 months), both the Williams and the Down samples are delayed by many months or years on both word comprehension and word production. The predicted separation between the two clinical groups does not emerge until the period of development covered by the
CDI:Toddlers (equivalent to normal children between 16-30 months), around the time when grammar begins (see below). At this point, both groups are approximately two years older than normal language-matched controls.

The late appearance of language in Williams Syndrome sets interesting limits on the degree of dissociation that can be observed between linguistic and nonlinguistic skills. We tentatively suggest that the similarities between Williams and Down Syndrome in the first stages of language development, and the late onset of language (both vocabulary and grammar) in both these groups, are evidence in favor of a revised version of the cognitive prerequisites to language view proposed in the 1970s (for reviews, see Bates and Snyder, 1987; Bates and Thal, 1991; Bates, Thal and Marchman, 1991). Specifically, we propose the following hypothesis:

Language cannot get off the ground until some minimal set of cognitive infrastructures are finally in place, including cognitive structures that are necessary though (perhaps) not sufficient for the establishment of reference and predication.

Dissociations between comprehension and production. Although there is considerable variability within both these clinical groups, we do not find more comprehension/production dissociations in either group than we would expect by chance (i.e. no more than we would expect if these children were drawn from the normal population). Furthermore, there are no significant differences between the two groups in comprehension/production profiles. The general picture appears to be one of delay rather than deviance, at least along this dimension.

Dissociations between grammar and the lexicon. In contrast with their findings for the Infant scale, Bellugi and colleagues report a sharp divergence between Williams Syndrome and Down Syndrome children during the period in which grammar is finally under way. However, the direction of this disparity is interesting, and perhaps somewhat surprising. Within the Williams group, grammatical development appears to be paced by vocabulary size, in the normal fashion. In fact, when these children are compared with lexically matched normal controls from the CDI sample, the relationship between grammar and vocabulary size is identical, following the nonlinear accelerating function described in Section II (see figure 4.10). In short, there is no evidence for a dissociation between grammatical and lexical development in the Williams group - at least not in this early phase of grammatical development.

By contrast, data for the Down Syndrome sample provide our first evidence to date for a significant dissociation between grammar and the lexicon. In particular, Down Syndrome children score significantly below the grammatical levels displayed by normal children (or Williams Syndrome children) matched for 
vocabulary size. We tentatively conclude that lexical size is a necessary but not sufficient condition for the acquisition of grammatical function words, the onset of word combinations, and growth in sentence complexity. This finding is compatible with reports on the selective impairment of grammar displayed by older Down Syndrome children, although the basis of the impairment is still unknown. It could be due to impairment of some domain-specific grammatical processor (e.g. Pinker, 1991), or, alternatively, it may derive from aspects of information processing that are only indirectly related to grammar. For example, Wang and Bellugi (1993) have presented evidence from older Williams and Down Syndrome individuals suggesting that there may be a double dissociation in the two groups between auditory digit span (significantly better in Williams Syndrome) and visual short-term memory on the Corsi sequential block touching task (significantly better in Down Syndrome). If Down Syndrome individuals suffer from a selective impairment in aspects of auditory processing (superimposed on their more general cognitive deficits), then it is not unreasonable to infer that they may be selectively impaired in the ability to detect, store and/or retrieve aspects of the auditory input that are low in phonological salience or stress (Leonard et al., 1992) and low in visual imagery (Goodglass and Menn, 1985).

It would be premature to conclude from these data that grammar is perfectly normal in Williams Syndrome but impaired in Down Syndrome. Studies of older Williams Syndrome individuals have uncovered subtle but significant deficits in certain aspects of grammatical morphology, including prepositions (Rubba and Klima, 1991) and grammatical gender (a study of Frenchspeaking Williams Syndrome individuals by KarmiloffSmith and Grant, 1993). There is still a great deal to be learned about the patterns of sparing and impairment that occur inside and outside of language in this puzzling syndrome (Carey and Grant, 1993; Mervis and Bertrand, 1993; Bellugi, Wang and Jernigan, 1994). For our purposes here, we may conclude that grammar does not develop ahead of the lexicon in the early phases of development, in any of the syndromes that we have studied to date including Williams Syndrome. However, the Down Syndrome data show that dissociations in the opposite direction can and do occur, with grammar falling behind vocabulary growth.

Variations in Style. Older children and adults with Williams Syndrome produce language that is novel and creative, although it is occasionally bizarre or inappropriate from a pragmatic point of view. They also show better receptive language skills (including judgments of grammaticality and interpretation of reversible passives) than we would expect on a formulaic/echolalic interpretation of their spontaneous speech. We can, therefore, reject the hypothesis that Williams Syndrome children are little tape-recorders, spewing back sentences that they heard the day before (i.e. "cocktail party syndrome" — Tew, 1975). In other words, Williams Syndrome does not constitute an extreme variant of holistic/formulaic style as it was originally conceived.

On the other hand, it should be clear from our review in Section III that the formulaic/echolalic view also fails to capture the speech produced by normal children at the holistic end of the analytic/holistic distribution. To be sure, there was an initial effort to characterize this dimension as a continuum from spontaneous production to imitative speech, and there is a small amount of evidence suggesting that holisticstyle children imitate more often than children at the analytic/telegraphic end of the distribution (e.g. immediate imitation of nonsense words at 20 months of age in Bates et al., 1988). However, other studies have shown that children who are high in referential style imitate more often when they are presented with a series of new names for novel objects (Leonard et al., 1991). In short, imitativeness may be a correlate or fellow traveler along this mysterious dimension, but it does not define the set of distinctions reviewed in Section III. We have proposed instead that the distinction between analytic and holistic style has more to do with factors like auditory short-term memory and the size of the unit a child can manage at a given point in time, degree of perceptual acuity (which helps some children to tune into inflections and function words at a relatively early point in lexical development), and/or a trade-off between speed and accuracy in early speech production. Armed with this refinement of the analytic/holistic dimension, let us reconsider the applicability of this dimension to language development in children with Williams and Down Syndrome.

In the Bellugi et al. study of Williams and Down Syndrome using the MacArthur CDI, parental reports have been analyzed to determine whether the two groups differ significantly in vocabulary composition, including referential style (controlling for vocabulary level) and closed-class style (in the period before 400 words, i.e. before the emergence of productive grammar). Results suggest that there is considerable variability within both groups along both of these dimensions, but no more than we would expect if children were drawn from the normal population (i.e. no more than we find in language-matched controls), and there were no significant differences between the two groups. In other words, there is no evidence in support of the idea that Down Syndrome children display a variant of analytic style while William Syndrome children display an extreme version of holistic style. On the other hand, as we pointed out in Section III, vocabulary composition scores offer an indirect and inadequate view of this important dimension of variation. More interesting information would come from studies that include repetition/imitation of nonsense words, phonological 
precision and consis-tency, frequency of certain construction types in spontaneous speech, auditory short-term memory, and so forth. In these respects, the predicted analogy may still hold (see also Thal, Bates and Bellugi, 1988). As we noted above, Williams Syndrome individuals perform significantly better than Down Syndrome children in an auditory memory task. Karmiloff-Smith and Grant, 1993) have also shown that older individuals with Williams Syndrome are actually more proficient than age-matched normal controls in a task that requires immediate repetition of novel words - even though they perform more poorly than controls in the assignment of grammatical gender for the same new words. In other words, we think the analytic/holistic dissociation may be fruitfully pursued in research on Williams and Down Syndrome, but only with the caveats that we have described here.

There is, of course, another possibility: the peculiar profiles of linguistic and nonlinguistic ability displayed by older children and adults with Williams Syndrome may reflect a qualitatively different form of brain organization for language, unlike anything that we have seen in any other normal or abnormal population (Jernigan and Bellugi, 1991; Jernigan, Bellugi, Sowell, Doherty and Hesselink, 1993). If this proves to be the case, then evidence from Williams Syndrome will have greatly expanded our understanding of variation and plasticity in language development.

\section{CONCLUSION}

We have reviewed evidence for individual differences in early language development in normal children, and in several contrasting clinical populations. Some consistent themes emerge from this survey.

First, there is enormous variability in rate of development during the passage from first words to grammar, in each and every one of our measures. These variations are so stable that they cannot be ascribed to noise, and so large that they are hard to explain with any single causal factor, maturational or environmental. We do not pretend to have exhausted the universe of possible biological and/or demographic causes for this variation, but we think it likely that a combination of factors will be required to explain individual differences of this magnitude (see also Huttenlocher et al., 1991; Hampson and Nelson, 1993). This includes a need for cross-linguistic studies of developmental variation, to complement crosslinguistic studies that compare the sequences and central tendencies that are observed in different language families (Slobin, 1985b, Volumes I and II; Slobin, 1993, Vol. III).

Second, we find robust evidence for a dissociation between comprehension and production in several normal and abnormal populations. A possible explanation for this dissociation comes from independent evidence suggesting that the two modalities are correlated with different nonlinguistic factors (in particular, comprehension is strongly associated with several different measures of cognitive development during the first and second year), and may be mediated by different neural systems (bilateral mechanisms for word comprehension, specialized lefthemisphere mechanisms for word production).

By contrast, we find a remarkably strong association between lexical and grammatical development in the period from 16-30 months of age (or its developmental equivalent in clinical populations). For example, there is a powerful nonlinear relationship between vocabulary size and the appearance of word combinations (usually between 50-100 words), and an equally strong exponential relationship between vocabulary size and increases in utterance length and sentence complexity (with a "take-off point" somewhere between 300-600 words). This relationship is also observed in late talkers, early talkers, children with focal brain injury, and children with Williams Syndrome. The robust nonlinear association between grammar and vocabulary size is predicted by recent connectionist models of morphological development (Plunkett and Marchman, 1993), and it is consistent with theories that underscore the role of perceptual and/or semantic bootstrapping or mass-action effects (Goodman and Nusbaum, 1994 ; O'Grady, 1987). We should point out, however, that this finding does not preclude the possibility of a grammar/semantics dissociation at some later point in development, when grammar achieves the status of a fluent, automatic skill (e.g. Marchman, Bates, Burkhardt and Good, 1991).

Down Syndrome children are the only group that we have seen so far in which there is a clear dissociation between grammar and vocabulary during this stage of language learning. For these children, early grammar falls far behind vocabulary growth, suggesting that lexical size is a necessary but not sufficient condition for the extraction of grammatical regularities. The nature of the limiting factor that creates the grammatical deficit in Down Syndrome is still unknown, but it may be related to limitations in auditory short-term memory (Wang and Bellugi, 1993).

We also reviewed the history and current status of a peculiar dimension of qualitative or stylistic variation that travels under many names. The most common name for this dimension of variation is "analytic $\mathrm{v}$. holistic style", although our review suggests that this may be an unfortunate choice of terms. To be sure, this dimension of individual differences cuts across specific ages and content domains (i.e. phonology, vocabulary, grammar), and it does seem to have something to do with the size and precision of the unit that children can handle (or prefer to use). But it has proven frustratingly difficult to operationalize this dimension (if it is indeed a single dimension). There are some serious confounds between developmental and stylistic variance in the vocabulary composition scores that have been used to assess language styles in previous studies. Propensity for imitation is clearly an associate of the style 
dimension, but it does not define that dimension. Furthermore, as several studies have shown (Thal and Bates, 1988b; Pine and Lieven, 1990; Thal, Bates and Zappia, in preparation), holistic style is not the same thing as frozen or formulaic speech, and can be a route into grammatical productivity. Our findings for children with focal brain injury offer little help in uncovering the neural bases of this dimension. The most obvious neural hypotheses receive no support in our results to date (e.g. identification of holistic style with the right hemisphere; identification of telegraphic style with limitations in Broca's area). The contrasting profiles presented by Williams Syndrome and Down Syndrome hold some promise in unravelling the basis of this mysterious contrast in learning styles, but most of the important work still lies before us. We have proposed that future work in this direction should focus not on simple measures of vocabulary composition, but on processing dimensions like auditory short-term memory, perceptual acuity, unit size, and a speedaccuracy trade-off in real-time language use. Needless to say, these are difficult variables to study in children under 3 years of age.

One conclusion seems uncontroversial: The Average Child is a fiction, a descriptive convenience like the Average Man or the Average Woman. Theories of language development can no longer rely on this mythical being. Any theory worth the name will have to account for the variations that are reliably observed in early language learning.

\section{REFERENCES}

Baldwin, D.A., \& Markman, E.M. (1989). Establishing word-object relations: A first step. Child Development, 60, 381-398.

Bates, E., Benigni, L., Bretherton, I., Camaioni, L., \& Volterra, V. (1979). The emergence of symbols: Cognition and communication in infancy. New York: Academic Press.

Bates, E., Bretherton, I., \& Snyder, L. (1988). From first words to grammar: Individual differences and dissociable mechanisms. New York: Cambridge University Press.

Bates, E., Camaioni, L., \& Volterra, V. (1975). The acquisition of performatives prior to speech. Merrill-Palmer Quarterly, 21, 205-226.

Bates, E., \& Carnevale, G.F. (1993). New directions in language development. Developmental Review, 13, 436-470.

Bates, E., Marchman, V., Thal, D., Fenson, L., Dale, P., Reznick, J.S., Reilly, J., \& Hartung, J. (1994 ). Developmental and stylistic variation in the composition of early vocabulary. Journal of Child Language.

Bates, E., \& Snyder, L. (1987). The cognitive hypothesis in language development. In I. Uzgiris \& J. McV. Hunt (Eds.), Research with scales of psychological development in infancy. Champaign-Urbana: University of Illinois Press.

Bates, E., \& Thal, D. (1991). Associations and dissociations in child language development. In J. Miller (Ed.), Research on child language disorders: A decade of progress. Austin, TX: ProEd.

Bates, E., Thal, D., \& Janowsky, J. (1992). Early language development and its neural correlates. In I. Rapin and S. Segalowitz (Eds.), Handbook of neuropsychology, Vol. 7: Child neuropsychology. Amsterdam, The Netherlands: Elsevier.

Bates, E., Thal, D., \& Marchman, V. (1991). Symbols and syntax: A Darwinian approach to language development. In N. Krasnegor, D. Rumbaugh, R. Schiefelbusch and M. Studdert-Kennedy (Eds.), Biological and behavioral determinants of language development. Hillsdale, NJ: Erlbaum.

Bates, E., Thal, D., Whitesell, K., Fenson, L., \& Oakes, L. (1989). Integrating language and gesture in infancy. Developmental Psychology, 25(6), 10041019.

Bellugi, U., Bihrle, A., Jernigan, T., Trauner, D., \& Doherty, S. (1990). Neuropsychological, neurological and neuroanatomical profile of Williams Syndrome children. American Journal of Medical Genetics, 6, 115-125.

Bellugi, U., Bihrle, A., Neville, H., Jernigan, T., \& Doherty, S. (1992). Language, cognition, and brain organization in a neurodevelopmental disorder. In M. Gunnar \& C. Nelson (Eds.), Developmental behavioral neuroscience (pp. 201232). Hillsdale, NJ: Erlbaum.

Bellugi, U., Marks, S., Bihrle, A.M.,\& Sabo, H. (1988). Dissociation between language and social functions in Williams Syndrome. In K. Mogford and D. Bishop (Eds.), Language development in exceptional circumstances. (pp. 177-189). New York: Churchill Livingstone Inc.

Bellugi, U., Sabo, H., and Vaid, J. (1988). Spatial deficits in children with Williams Syndrome. In J. Stiles-Davis, M. Kritchevsky, and U. Bellugi (Eds.), Spatial Cognition: Brain Bases and Development. Hillsdale, NJ: Erlbaum.

Bellugi, U., Wang, P., \& Jernigan, T. (1994). Williams Syndrome: An unusual neuropsychological profile. In S. Broman \& J. Grafman (Eds.), Atypical cognitive deficits in developmental disorders: Implications for brain function. Hillsdale, NJ: Erlbaum.

Benedict, H. (1979). Early lexical development: Comprehension and production. Journal of Child Language, 6. 183-200.

Bertrand, J., Mervis, C.B., Rice, C.E., \& Adamson, L. (1993, March). Development of joint attention by a toddler with Williams Syndrome. Paper presented at the Gatlinburg Conference on Research and 
Theory in Mental Retardation and DevelopmentalCrystal, D. (1974). Review of R. Brown, 'A first language: Disabilities, Gatlinburg, TN.

Bickerton, D. (1984). The language bioprogram hypothesis. The Behavioral and Brain Sciences, 7 , 173-187.

Bihrle, A. M., Bellugi, U., Delis M., \& Marks, S. (1989). Seeing either the forest or the trees: Dissociation in visuospatial processing. Brain and Cognition, 11, 37-49.

Bliss, L.S. (1989). Selected syntactic usage of language-impaired children. Journal of Communication Disorders, 22, 277-289.

Bloom, L. (1970). Language development: Form and function in emerging grammars. Cambridge, MA: MIT Press.

Bloom, L., Lightbown, L., \& Hood, L. (1975). Structure and variation in child language. Monographs for the Society for Research in Child Development, 40, Serial \#160.

Braine, M.D.S. (1963). The ontogeny of English phrase structure: The first phase. Language, 39, 313.

Brown, R. (1973). A first language: The early stages. Cambridge, MA: Harvard University Press.

Brownell, C. (1988). Combinatorial skills: Converging developments over the second year. Child Development, 59, 675-685.

Camaioni, L., Caselli, M.C., Longobardi, E., \& Volterra, V. (1991). A parent report instrument for early language assessment. First Language, 11, 345-359.

Carey, S., \& Grant, J. (1993, March). Conceptual structure of adults/adolescents with Williams syndrome. Paper presented at the 60th Annual Meeting of the Society for Research in Child Development, New Orleans, LA.

Caulfield, M.B., Fischel, J.E., DeBaryshe, B.D., \& Whitehurst, G.J. (1989). Behavioral correlates of developmental expressive language disorder. Journal of Abnormal Child Psychology, 17, 187201.

Chomsky, N. (1986). Knowledge of language: Its nature, origin, and use. New York: Praeger.

Chomsky, N. (1988). Language and problems of knowledge. MIT Press.

Chapman, R., \& Miller, J. (1975). Word order in early two- and three-word utterances: Does production precede comprehension? Journal of Speech and Hearing Research, 18, 355-371.

Crain, S. (1992). Language acquisition in the absence of experience. Behavioral and Brain Sciences, 14, 597-611.

Crain-Thoreson, C., \& Dale, P.S. (1992). Do early talkers become early readers? Linguistic precocity, preschool language, and emergent literacy. Developmental Psychology, 28, 421-429.

307.

Dale, P.S., Bates, E., Reznick, J.S., \& Morisset, C. (1989). The validity of a parent report instrument of child language at 20 months. Journal of Child Language, 16, 239-249.

Dale, P.S., Robinson, N.M., \& Crain-Thoreson, C. (1992). Linguistic precocity and the development of reading: A final report. Manuscript submitted for publication.

Dall'Oglio, A.M., Bates, E., Volterra, V., Di Capua, M., \& Pezzini, G. (1992). Early cognition, communication and language in children with focal brain injury. (Tech. Rep. No. 9202). La Jolla: University of California, San Diego, Project in Cognitive Neurodevelopment, Center for Research in Language.

Dixon, W.E. Shore, C. (1992, May). Confirming linguistic styles. Paper presented at the International Conference on Infant Studies, Miami Beach, FL.

Dixon, W.E., \& Shore, C. (1993, March). Short-term stability and temperamental predictors of linguistic style. Poster presented at the 60th Annual Meeting of the Society for Research in Child Development, New Orleans, LA.

Dore, J. (1974). A pragmatic description of early language development. Journal of Psycholinguistic Research, 4, 423-430.

Dromi, E. (1987). Early lexical development. New York: Cambridge University Press.

Dukette, D., \& Stiles, J. (1991, April). Spatial pattern analysis in preschool children: Evidence from a matching task using hierarchical letter stimuli. Paper presented at the biannual meeting of the Society for Research in Child Development, Seattle.

Feldman, H., Holland, A., Kemp, S., \& Janosky, J. (1992). Language development after unilateral brain injury. Brain and Language, 42, 89-102.

Fenson, L., Bates, E., Dale, P.S., Thal, D., \& Reznick, J.S. (in preparation). Variability in early communicative development.

Fenson, L., Dale, P.S., Reznick, J.S., Thal, D., Bates, E., Hartung, J., Pethick, S., \& Reilly, J. (1993). The MacArthur Communicative Development Inventories: User's guide and technical manual. San Diego: Singular Publishing Group.

Fischel, J.E., Whitehurst, G.J., Caulfield, M.B., \& DeBaryshe, B.D. (1989). Language growth in children with expressive language delay. Pediatrics, 82, 218-227.

Fischel, J.E., Whitehurst, G., \& Connors, G. (1987, April). Language growth in children with expressive language delay. Paper presented at the 
biennial meeting of the Society for Research in Child Development, Baltimore, MD.

Fodor, J.A. (1983). The modularity of mind. Cambridge, MA: MIT Press.

Fortescue, M., \& Lennert Olsen, L. (1992). The acquisition of West Greenlandic. In D. Slobin (Ed.), The crosslinguistic study of language acquisition (Vol. 3, pp. 111-220). Hillsdale, NJ: Erlbaum.

Gerken, L. (1994 ) Sentential processes in early language. In J.C. Goodman \& H.C. Nusbaum (Eds.), The development of speech perception: Transitions from speech sounds to spoken words. Cambridge, MA: MIT Press.

Gleitman, L., \& Wanner, E. (1982). Language acquisition: The state of the state of the art. In E. Wanner \& L. Gleitman (Eds.), Language acquisition: The state of the art. New York: Cambridge University Press.

Goldfield, B.A., \& Reznick, J.S. (1990). Early lexical acquisition: Rate, content, and the vocabulary spurt. Journal of Child Language, 17(1), 171-184.

Goldfield, B.A., \& Snow, C. (1985). Individual differences in language acquisition. In J. Gleason (Ed.), Language development. Columbus: Merrill Publishing Co.

Goldin-Meadow, S., Seligman, M.E.P., \& Gelman, R. (1976). Language in the two-year-old. Cognition, 4, 189-202.

Goodglass, H. , \& Menn, L. (1985). Is agrammatism a unitary phenomenon? In M.-L. Kean (Ed.), Agrammatism. New York: Academic Press.

Goodman, J.C., \& Nusbaum, H.C. (Eds.). (1994 ). The development of speech perception: Transitions from speech sounds to spoken words. Cambridge, MA: MIT Press.

Goodman, J. C., Nusbaum, H. C., Lee, L., \& Broihier, K. (1990). The effects of syntactic and discourse variables on the segmental intelligibility of speech. The Proceedings of the 1990 International Conference on Spoken Language Processing (pp. 393-396). Kobe, Japan: The Acoustical Society of Japan.

Gopnik, A., \& Meltzoff, A. (1986). Relations between semantic and cognitive development in the oneword stage - the specificity hypothesis. Child Development, 57, 1040-1053.

Gopnik, A., \& Meltzoff, A. (1987). The development of categorization in the second year and its relation to other cognitive and linguistic developments. Child Development, 58, 1523-1531.

Greenfield, P. M. (1991). Language, tools and brain: The ontogeny and phylogeny of hierarchically organized sequential behavior. Behavioral and Brain Sciences, 14, 531-550.
Hampson, J., \& Nelson, K. (1993). Relation of maternal language to variation in rate and style of language acquisition. Journal of Child Language.

Harding, C.G., \& Golinkoff, R. (1979). The origins of intentional vocalizations in prelinguistic infants. Child Development, 50, 33-40.

Hecaen, H. (1976). Acquired aphasia in children and the ontogenesis of hemispheric functional specialization. Brain and Language, 3, 114-134.

Hirsh-Pasek, K., \& Golinkoff, R.M. (1991). Language comprehension: A new look at some old themes. In N. Krasnegor, D. Rumbaugh, R. Schiefelbusch and M. Studdert-Kennedy (Eds.), Biological and behavioral determinants of language development. Hillsdale, NJ: Erlbaum.

Horgan, D. (1981). Rate of language acquisition and noun emphasis. Journal of Psycholinguistic Research, 10, 629-640.

Huttenlocher, Haight, W., Bryk, A., Seltzer, M., \& Lyons, J. (1991). Early vocabulary growth: Relation to language input and gender. Developmental Psychology, 27, 236-248.

Jernigan, T., \& Bellugi, U. (1990). Anomalous brain morphology on magnetic resonance images in Williams Syndrome and Down Syndrome. Archives of Neurology, 47, 429-533.

Jernigan, T. L., Bellugi, U., Sowell, E., Doherty, S., \& Hesselink, J. R. (1993). Cerebral morphological distinctions between Williams and Down syndromes. Archives of Neurology, 50, 186-191.

Johnston, J.R., \& Kamhi, A.G. (1984). Syntactic and semantic aspects of the utterances of languageimpaired children: The same can be less. MerrillPalmer Quarterly, 30, 65-85.

Johnston, J.R., \& Schery, T.K. (1976). The use of grammatical morphemes by children with communication disorders. In D.M. Morehead \& A.E. Morehead (Eds.), Normal and deficient child language. Baltimore, MD: University Park Press.

Kagan, J. (1971). Change and continuity in infancy. New York: John Wiley and Sons.

Kahn, L., \& James, S. (1983). Grammatical morpheme development in three language-disordered children. Journal of Childhood Communication Disorders, 6, 85-100.

Karmiloff-Smith, A. (1992). Beyond modularity: A developmental perspective on cognitive science. Cambridge, MA: MIT Press.

Karmiloff-Smith, A., \& Grant, J. (1993, March). Linguistic and cognitive development in Williams syndrome: A window on the normal mind. Poster presented at the 60th Annual Meeting of the Society for Research in Child Development, New Orleans, LA.

Kelly, C. A., \& Dale, P.S. (1989). Cognitive skills associated with the onset of multiword utterances. 
Journal of Speech and Hearing Research, 32, 645656.

Klee, T., \& Fitzgerald, M.D. (1985). The relation between grammatical development and mean length of utterance in morphemes. Journal of Child Language, 12, 251-269.

Lamb, M.R., Robertson, L.C., \& Knight, R.T. (1990). Component mechanisms underlying the processing of hierarchically organized patterns: Inferences from patients with unilateral cortical lesions. Journal of Experimental Psychology: Learning, Memory, and Cognition, 16, 471-483.

Lenneberg, E.H. (1967). Biological foundations of language. New York: Wiley.

Leonard, L., Bortolini, U., Caselli, M., McGregor, K., \& Sabbadini, L. (1992). Two accounts of morphological deficits in children with Specific Language Impairment. Language Acquisition.

Leopold, W.F. (1949). Speech development of a bilingual child: A linguist's record. Evanston, IL: Northwestern University Press.

MacWhinney, B. (1989). Competition and connectionism. In In B. MacWhinney \& E. Bates (Eds.), The crosslinguistic study of sentence processing. New York: Cambridge University Press.

MacWhinney, B. (1991a). Connectionism as a framework for language acquisition theory. In J. Miller (Ed.), Research on child language disorders: A decade of progress. Austin, TX: ProEd.

MacWhinney, B. (1991b). Implementations are not conceptualizations: Revising the verb-learning model. Cognition, 40, 121-157.

Marchman, V. (1993). Constraints on plasticity in a connectionist model of the English past tense. Journal of Cognitive Neuroscience, 5(2), 215-234.

Marchman, V., \& Bates, E. (1994 ). Continuity in lexical and morphological development: A test of the critical mass hypothesis. Journal of Child Language.

Marchman, V., Bates, E., Burkhardt, A., \& Good, A. (1991). Functional constraints on the acquisition of the passive: Toward a model of the competence to perform. First Language, 11, 65-92.

Marchman, V., Miller, R., \& Bates, E. (1991). Babble and first words in children with focal brain injury. Applied Psycholinguistics, 12, 1-22.

McCall, R., Eichorn, D., \& Hogarty, P. (1977). Transitions in early mental development. Monographs of the Society for Research in Child Development, Serial \#171.

McCune-Nicolich, L. (1981). Toward symbolic functioning: Structure of early pretend games and potential parallels with language. Child Development, 52, 785-797.
McCune-Nicolich, L., \& Bruskin, C. (1982). Combinatorial competency in play and language. In D. Pepler \& K. Rubin (Eds.), The play of children: Current theory and research (pp. 30-45). New York: Karger.

Menn, L. (1976/1979). Pattern, control, and contrast in beginning speech. Doctoral dissertation, University of Illinois, circulated 1979 by Indiana University Linguistics Club.

Mervis, C.B., \& Bertrand, J. (1993, March). Early language and cognitive development: Implications of research with children who have Williams syndrome or Down syndrome. Paper presented at the 60th Anniversary Meeting of the Society for Research in Child Development, New Orleans, LA.

Miller, J.F. (1981). (With chapters by Thomas M. Klee and Rhea Paul and Robin S. Chapman, and contributions and procedures by Ursula Bellugi). Assessing language production in children: Experimental procedures. Baltimore: University Park Press.

Miller, J. (1987). Language and communication characteristics of children with Down Syndrome. In S. Pueschel, C. Tingey, J. Rynders, A Crocker and D. Crutcher (Eds.), New perspectives on Down Syndrome (pp. 233-262). Baltimore: Brooks Publishing Co.

Miller, J. (1988). The developmental asynchrony of language development in children with Down Syndrome. In L. Nadal (Ed.) The psychobiology of Down Syndrome. New York: Academic Press.

Miller, J. (in press-a). Lexical acquisition in children with Down Syndrome. In R.S. Chapman (Ed.) Child talk: Advances in language acquisition. Year Book Medical Publishers, Inc.

Miller, J. (in press-b). The development of speech and language in children with Down Syndrome. In E. McCoy and I. Lott (Eds.) Clinical care for persons with Down Syndrome. Academic Press.

Mills, D. (1993, October). Differentiation of neural subsystems for open- and closed-class words during primary language acquisition. Paper presented at the annual meeting of the American Psychological Association, Chicago.

Mills, D., Coffey, S., \& Neville, H. (in press). Language acquisition and cerebral specialization in 20-month-old children. Journal of Cognitive Neuroscience.

Mills, D., Coffey, S., \& Neville, H. (1993). Changes in cerebral organization in infancy during primary language acquisition. In G. Dawson \& K. Fischer (Eds.), Human behavior and the developing brain. New York: Guilford Publications.

Nelson, K E. (1973). Structure and strategy in learning to talk. Monograph of the Society for Research in Child Development, 38, (1 \& 2, Serial \#149). 
Nelson, K.E. (1981). Individual differences in language development: Implications for development and language. Developmental Psychology, 17, 170-187.

Nelson, K.E., Baker, N., Denninger, M., Bonvillian, J., \& Kaplan, B. (1985). "Cookie" versus "Do-itagain": Imitative-referential and personal-socialsyntactic-initiating styles in young children. Linguistics, 23:3.

Nelson, K.E. , \& Bonvillian, J. (1978). Concepts and words in the two-year-old: Acquisition of concept names under controlled conditions. In K.E. Nelson (Ed.), Children's language (Vol. I). New York: Gardner Press.

Nicolich, L. (1977). Beyond sensorimotor intelligence: Assessment of symbolic maturity through analysis of pretend play. Merrill-Palmer Quarterly, 23, 8999.

O'Grady, W. (1987). Principles of grammar learning. Chicago: University of Chicago Press.

Oviatt, S. L. (1980). The emerging ability to comprehend language: An experimental approach. Child Development, 51, 97-106.

Paul, R. (1991). Profiles of toddlers with slow expressive language development. Topics in Language Disorders, 11:4, 1-13.

Paul, R., Spangle-Looney, S., \& Dahm, P.S. (1991). Communication and socialization skills at ages 2 and 3 in late-talking young children. Journal of Speech and Hearing Research, 4, 858-865.

Peters, A. (1977). Language-learning strategies: Does the whole equal the sum of the parts? Language, 53, 560-573.

Peters, A. (1983). The units of language acquisition. Cambridge: Cambridge University Press.

Pickett, J.M., \& Pollack, I. (1963). Intelligibility of excerpts from fluent speech: Effects of rate of utterance and duration of excerpt. Language and Speech, 7, 151-164.

Pine, J.M., \& Lieven, E. (1990). Referential style at 13 months: Why age-defined cross-sectional measures are inappropriate for the study of strategy differences in early language development. Journal of Child Language, 17, 625-631.

Pinker, S. (1991). Rules of language. Science, 253, 530-535.

Plunkett, K. (1993). Lexical segmentation and vocabulary growth in early language acquisition. Journal of Child Language, 20, 43-60.

Plunkett, K., \& Marchman, V. (1991). U-shaped learning and frequency effects in a multi-layered perceptron: Implications for child language acquisition. Cognition, 38, 43-102.

Plunkett, K., \& Marchman, V. (1993). From rote learning to system building: Acquiring verb morphology in children and connectionist nets. Cognition , 48, 21-69.
Pollack, I., \& Pickett, J.M. (1963). The intelligibility of excerpts from conversation. Language and Speech, 6, 165-171.

Ramer, A.L.H. (1976). Syntactic styles in emerging language. Journal of Child Language, 3, 49-62.

Rasmussen, T., \& Milner, B. (1977). The role of early left-brain injury in determining lateralization of cerebral speech functions. Annals of the New York Academy of Sciences, 299, 355-369.

Rescorla, L.A. (1981). Category development in early language. Journal of Child Language, 8, 225-238.

Rescorla, L.A. (1989). The Language Development Survey: A screening tool for delayed language in toddlers. Journal of Speech and Hearing Disorders, 54, 587-599.

Rescorla, L.A. (1993, March). Outcome of toddlers with specific expressive language delay (SELD) at ages 3, 4, 5, and 6. Poster presented at the 60th Annual Meeting of the Society for Research in Child Development, New Orleans, LA.

Rescorla, L., \& Goossens, M. (1992). Symbolic play development in toddlers with expressive specific language impairment. Journal of Speech and Hearing Research, 6, 1290-1302.

Rescorla, L., \& Schwartz, E. (1990). Outcome of toddlers with specific expressive language delay. Applied Psycholinguistics, 11, 393-408.

Reznick, J.S., \& Goldfield, B.A. (1992). Rapid change in lexical development in comprehension and production. Developmental Psychology, 28, 406413.

Reilly, J., Klima, E.S., \& Bellugi, U. (1991). Once more with feeling: Affect and language in atypical populations. Development and Psychopathology, 367-391.

Robertson, L.C., \& Delis, D.C. (1986). "Part-whole" processing in unilateral brain-damaged patients: Dysfunction of hierarchical organization. Neuropsychologia, 24(3), 363-370.

Robinson, N.M., Dale, P.S., \& Landesman, S. (1990). Validity of Stanford-Binet IV with linguistically precocious toddlers. Intelligence, 14, 173-186.

Rubba, J., \& Klima, E.S. (1991). Preposition use in a speaker with Williams Syndrome: Some cognitive grammar proposals. Center for Research in Language Newsletter Vol. 6, No. 1. University of California, San Diego.

Satz, P., Strauss, E., \& Whitaker, H. (1990). The ontogeny of hemispheric specialization: Some old hypotheses revisited. Brain and Language, 38, 596-614.

Scarborough, H.S. (1990). Index of productive syntax. Applied Psycholinguistics, 11, 1-21.

Scarborough, H.S., \& Dobrich, W. (1990). Development of children with early language 
delay. Journal of Speech and Hearing Research, 33, 70-83.

Shore, C. (1986). Combinatorial play: Conceptual development and early multiword speech. Developmental Psychology, 22, 184-190.

Shore, C., Bates, E., Bretherton, I., Beeghly, M., \& O'Connell, B. (1990). Vocal and gestural symbols: Similarities and differences from 13 to 28 months. In V. Volterra and C.J. Erting (Eds.), From gesture to language in hearing and deaf children (pp. 7992). New York: Springer-Verlag.

Shore, C., O'Connell, B., \& Bates, E. (1984). First sentences in language and symbolic play. Developmental Psychology, 20, 872-880.

Slobin, D. (1985a). Crosslinguistic evidence for the language-making capacity. In D. Slobin (Ed.), The crosslinguistic study of language acquisition (Vol. 2, pp. 1157-1256). Hillsdale, NJ: Erlbaum.

Slobin, D. (Ed.). (1985b). The crosslinguistic study of language acquisition (Vols. $1 \& 2$ ). Hillsdale, NJ: Erlbaum.

Slobin, D. (Ed.). (1992). The crosslinguistic study of language acquisition (Vol. 3). Hillsdale, $\mathrm{NJ}$ : Erlbaum.

Snyder, L., Bates, E., \& Bretherton, I. (1981). Content and context in early lexical development. Journal of Child Language, 8, 565-582.

Snyder, L. S. (1978). Communicative and cognitive abilities and disabilities in the sensorimotor period. Merrill-Palmer Quarterly, 24, 161-180.

Steckol, K., \& Leonard, L., (1979). The use of grammatical morphemes by normal and languageimpaired children. Journal of Communication Disorders, 12, 291-301.

Stiles, J., \& Thal, D. (1993). Linguistic and spatial cognitive development following early focal brain injury: Patterns of deficit and recovery. In $\mathrm{M}$. Johnson (Ed.), Brain development and cognition: A reader (pp.643-664). Oxford: Blackwell Publishers.

Sugarman, S. (1983). Empirical versus logical issues in the transition from prelinguistic to linguistic communication. In R.M. Golinkoff (Ed.), The transition from prelinguistic to linguistic communication. Hillsdale, NJ: Erlbaum.

Tew, B. (1975). The "Cocktail Party Syndrome" in children with hydrocephalus and spina bifida. British Journal of Disorders of Communication, 41, 89-101.

Thal, D., \& Bates, E. (1988a). Language and gesture in late talkers. Journal of Speech and Hearing Research, 31,115-123.

Thal, D., \& Bates, E. (1988b, November.). Relationships between language and cognition: Evidence from linguistically precocious children. Paper presented to the Annual Convention of the
American Speech-Language-Hearing Associa-tion, Boston, MA.

Thal, D., Bates, E., and Bellugi, U. (1989). Language and cognition in two children with Williams Syndrome. Journal of Speech and Hearing Research, 3, 489-500.

Thal, D., Bates, E., \& Fenson, L. (in preparation). Characteristics of toddlers with delayed language development.

Thal, D., Bates, E., \& Zappia, J. (in preparation). Relationships between lexicon and grammar: Evidence from linguistically precocious toddlers.

Thal, D., Cleveland, S., \& Oroz, M. (in preparation). Lexical and grammatical development in normal and late-talking toddlers.

Thal, D., Marchman, V., Stiles, J., Aram, D., Trauner, D., Nass, R., \& Bates, E. (1991). Early lexical development in children with focal brain injury. Brain and Language, 40, 491-527.

Thal, D., \& Schick, K. (in preparation). Relationships between language and gesture in linguistically precocious toddlers.

Thal, D., Tobias, S., \& Morrison, D. (1991). Language and gesture in late talkers: A one year follow-up. Journal of Speech and Hearing Research, 34:3, 604-612.

Van Geert, P. (1991). A dynamic systems model of cognitive and language growth. Psychological Review, 98, 3-53.

Vargha-Khadem, F., Isaacs, E., Van der Werf, S., Robb, S., \& Wilson, J. (1992). Development of intelligence and memory in children with hemiplegic cerebral palsy: The deleterious consequences of early seizures. Brain, 115, 315329.

Vihman, M. (1981). Phonology and the development of the lexicon: Evidence from children's errors. Journal of Child Language, 8, 239-264.

Wang, P.P., \& Bellugi, U. (1993). Evidence from two genetic syndromes for a dissociation between verbal and visual short-term memory. Manuscript submitted for publication.

Wang, P.P., Doherty, S., Hesselink, J.H., \& Bellugi, U. (1992). Callosal morphology concurs with neurobehavioral and neuropathological findings in two neurodevelopmental disorders. Archives of Neurology, 49, 407-411.

Wang, P.P., Hesselink, J.H., Jernigan, T., Doherty, S., \& Bellugi, U. (1992). Specific neurobehavioral profile of Williams syndrome is associated with neocerebellar hemispheric preservation. Neurology, 42, 1999-2002.

Wells, R. (1985). Language development in the preschool years. Cambridge University Press. 
Whitehurst, G., Fischel, J., Arnold, D., \& Lonigan, C. (1992). Evaluating outcomes with children with expressive language delay. In $\mathrm{W}$. Warren \& J. Reichle (Eds.), Causes and Effects in Communication and Language Intervention (pp. 277-314). Baltimore: Paul Brookes.

Wong-Fillmore, L. (1979). Individual differences in second-language acquisition. In C.J. Fillmore, D. Kempler \& W. Wang (Eds.), Individual differences in language ability and language behavior. New York: Academic Press.

Woods, B.T., \& Teuber, H.L. (1978). Changing patterns of childhood aphasia. Annals of Neurology, 3, 272-280.

Wulfeck, B., Trauner, D., \& Tallal, P. (1991). Neurologic, cognitive and linguistic features of infants after early stroke. Pediatric Neurology, 7, 266-269. 


\section{TABLE 1: INDIVIDUAL DIFFERENCES IN LANGUAGE DEVELOPMENT: \\ SUMMARY OF CLAIMS IN THE LITERATURE.}

Strand 2

\section{Semantics}

High proportion of nouns

in first 50 words

Single words in early speech

Imitates object names

Greater variety within lexical categories

Meaningful elements only

High adjective use

Context-flexible use of names

Rapid vocabulary growth

Telegraphic in Stage I

Refers to self and others

by name in State I

Noun phrase expansion

Morphological overgeneralization

Consistent application of rules

Novel combinations

Imitation is behind spontaneous speech speech

Fast learner

\section{Pragmatics}

Object-oriented

Declarative

Low variety in speech acts

Word-oriented

High intelligibilty

Segmental emphasis

Consistent pronunciation across word tokens
Low proportion of nouns in first 50 words

Formulae in early speech

Unselective imitation

Less variety within lexical categories

Use of "dummy" words

Low adjective use

Context-bound use of names

Slower vocabulary growth

\section{Grammar}

Inflections and function words in Stage I

Refers to self and others by pronoun in State I

Verb phrase expansion

Morphological undergeneralization

Inconsistent application of rules

Frozen forms

Imitation is ahead of spontaneous

Slow learner

Person-oriented

Imperative

High variety in speech acts

\section{Phonology}

Intonation-oriented

Low intelligibility

Suprasegmental emphasis

Variable pronunciation across word tokens

\section{Demographic Variables}

Female

Firstborn

Higher SES
Male

Laterborn

Lower SES 


\section{Social Explanations}

Exogenous

Endogenous

Within language proper

Between language and cognition

Interhemispheric

Intrahemispheric

Unidimensional

Multidimensional
Maternal style and input

- Object vs. person focus

- Does or does not imitate the child

Social class

- Elaborated vs. restricted code

Temperament

- Object vs. person orientation

- Reflective vs. impulsive approach to problems

\section{Linguistic Explanations}

- Language function vs. language form

- Open- vs. closed-class lexicon or semantics vs. grammar

- Word order vs. morphology

- Environmentally sensitive and insensitive processes

\section{Neurological Explanations}

- Right- vs. left-hemisphere emphasis

- Anterior vs. posterior emphasis within the dominant hemisphere

\section{Cognitive Explanations}

- General intelligence

- Field dependence - independence

- Analytic vs. Gestalt/holistic processing

- Analytic vs. imitative learning mechanisms

- Patterners vs. dramatists

- Information-sensitive vs. frequency-sensitive

- Comprehension-driven vs. production-driven

- Analysis for understanding vs. analysis for reproduction 
TABLE 3: EXAMPLES OF LANGUAGE PRODUCTION

BY TWO VERY EARLY TALKERS (from Thal \& Bates, 1988b)

SARAH:

Age:

Vocabulary

Vocabulary age:

MLU:

MLU age:
17 Months Old

596 words

30 months

2.13

28 months

\section{MARYANN:}

Age:

Vocabulary:

Vocabulary age:

MLU

MLU age:
21 Months Old

627 words

$>30$ months

1.19

20 months
Where cup went?

Where chair went?

Teddy bear went?

Baby doing?

Wanna walk e baby.

Wanna put it on.

Wanna go ride it.

Want mom get off.

Daddy take her. (referring to self)

Help with the apple.

Can't get the teddy bear.

Teddybear the bath.

Too much carrots on the dish.

Move it around.

Clean e bottom.

Put ne sofa.

Put in eye.

Mommy wear hat.

Mommy smell it.

Mommy read the book.

Mommy sit down.

Find Becky.

See Becky in the morning.

Becky is nice.

Saw Becky and goats.
Pretty.

Cute.

Big.

Round.

Dry.

Hungry.

Wet.

Different.

Enough.

Else.

More.

Minute.

Brushing.

Hiding.

Baby crying.

Hold.

Hold it.

Dropped it.

Bring it.

Falling.

Fell.

Talk.

Talking.

Wash'em.

Shirt on.

Teddy up.

Mommy shoe. 
Figure 4.1 Word comprehension on the MacArthur CDI Infant Scale.

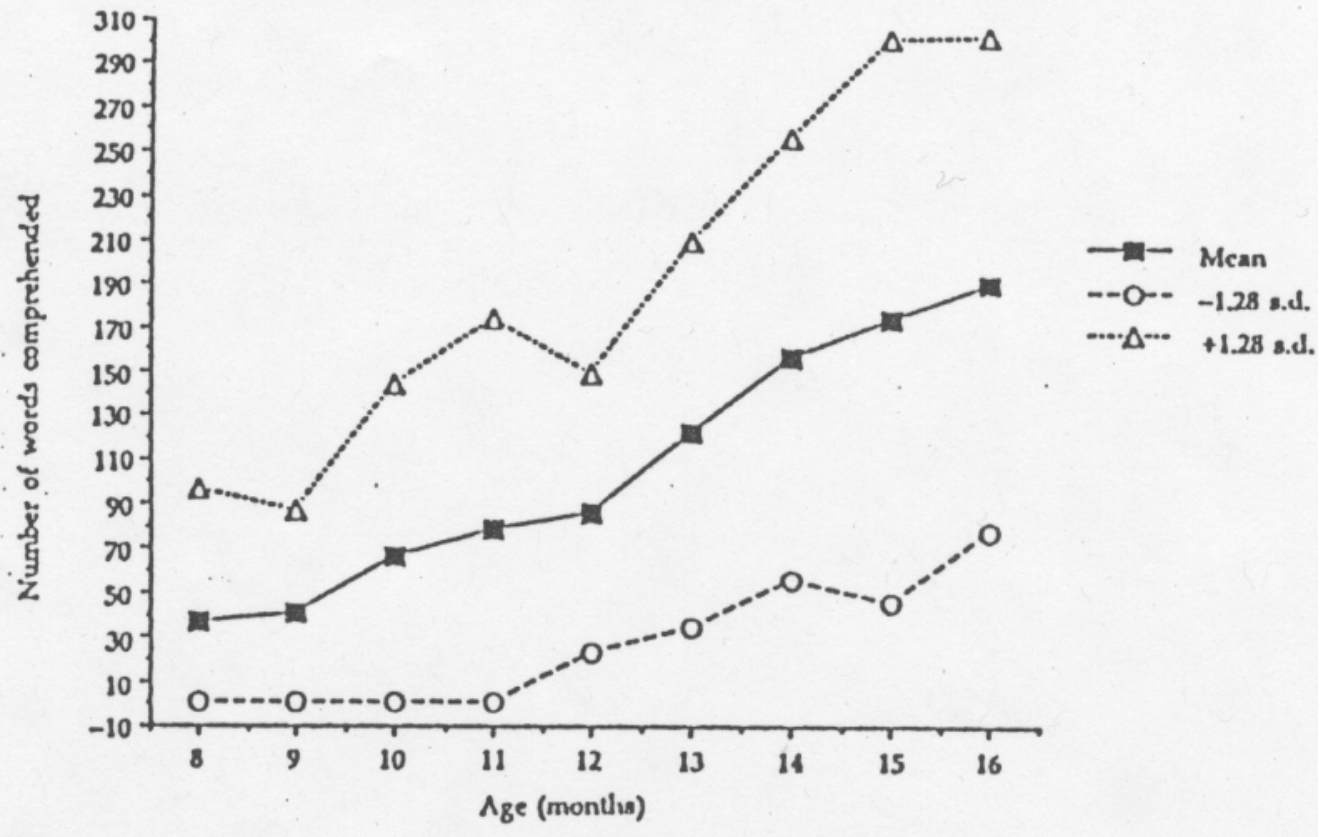

Figure 4.2 Word production on the MacArthur CDI Infant Scale.

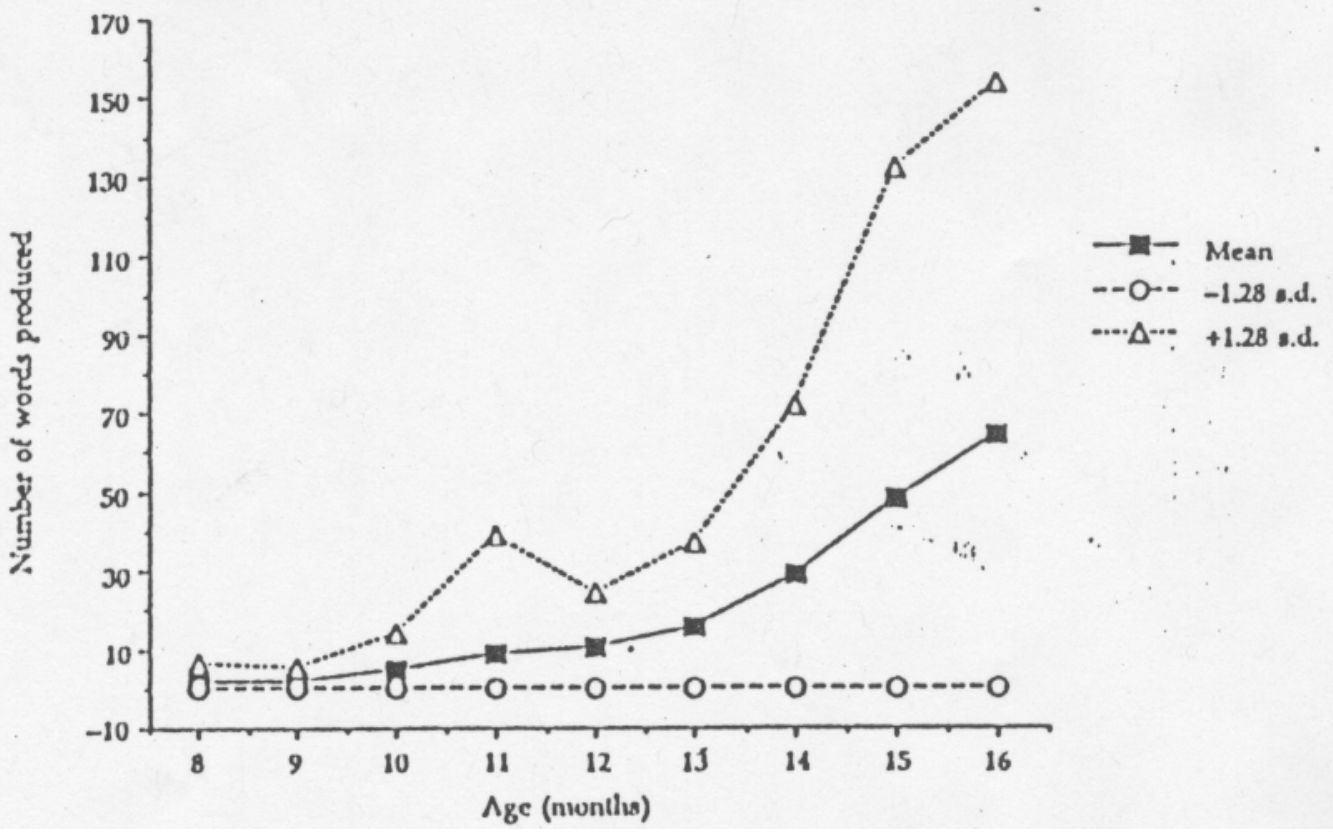


Figure 4.3 Word production on the MacArthur CDI Toddler Scale.

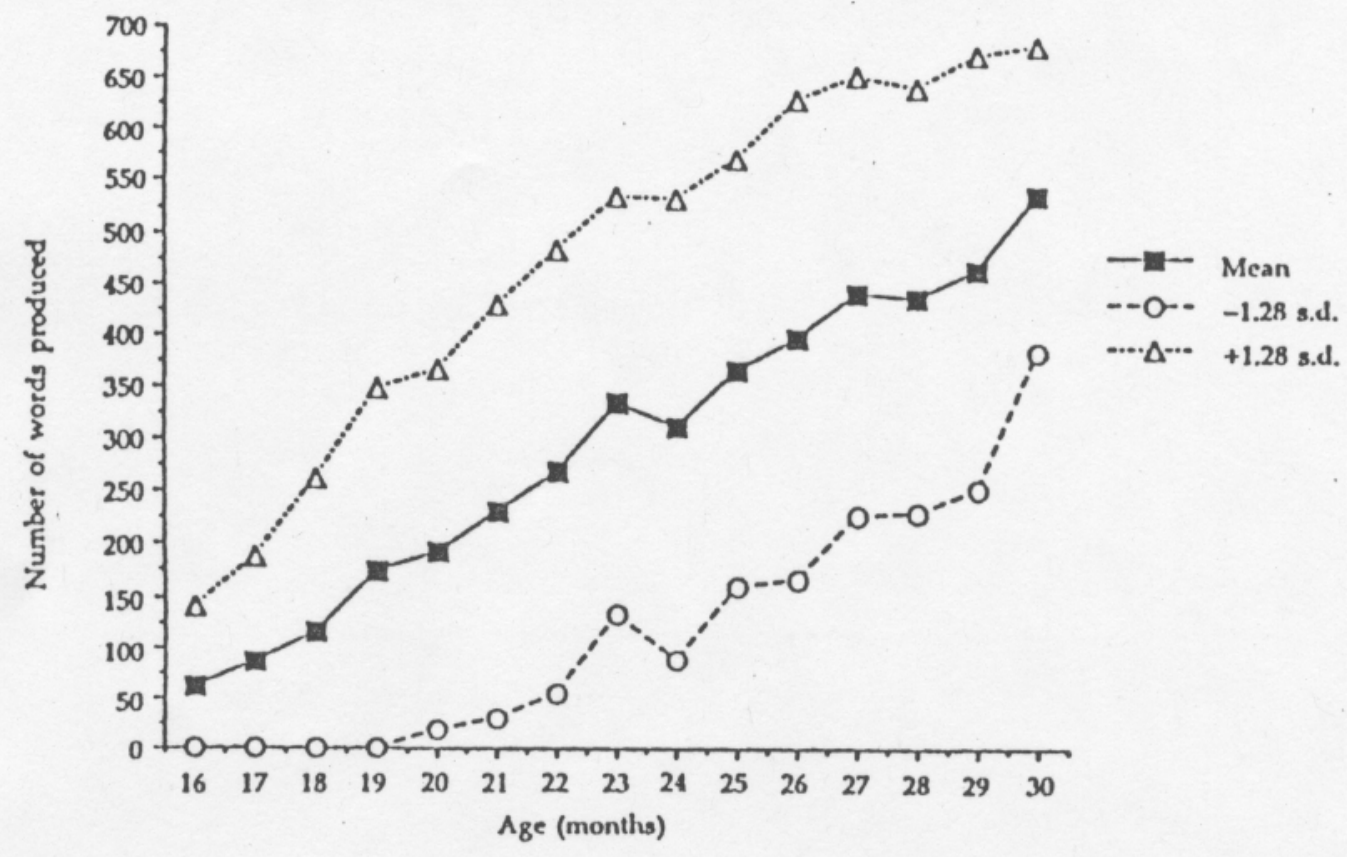

Figure 4.4 Percent children combining words as a function of age on the MacArthur CDI Toddler Scale.

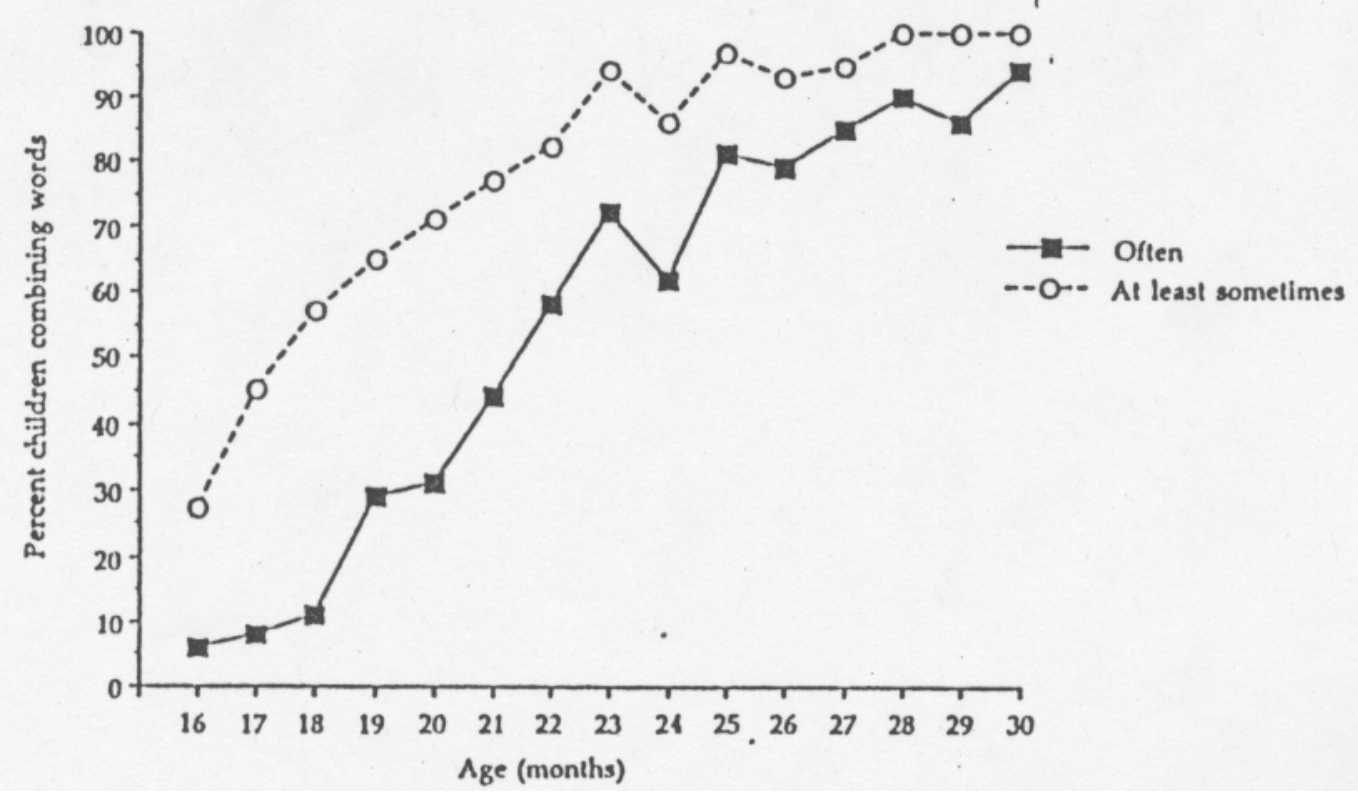


Figure 4.5 Granmatical complexity scores on the MacArthur CDI Toddler Scale.

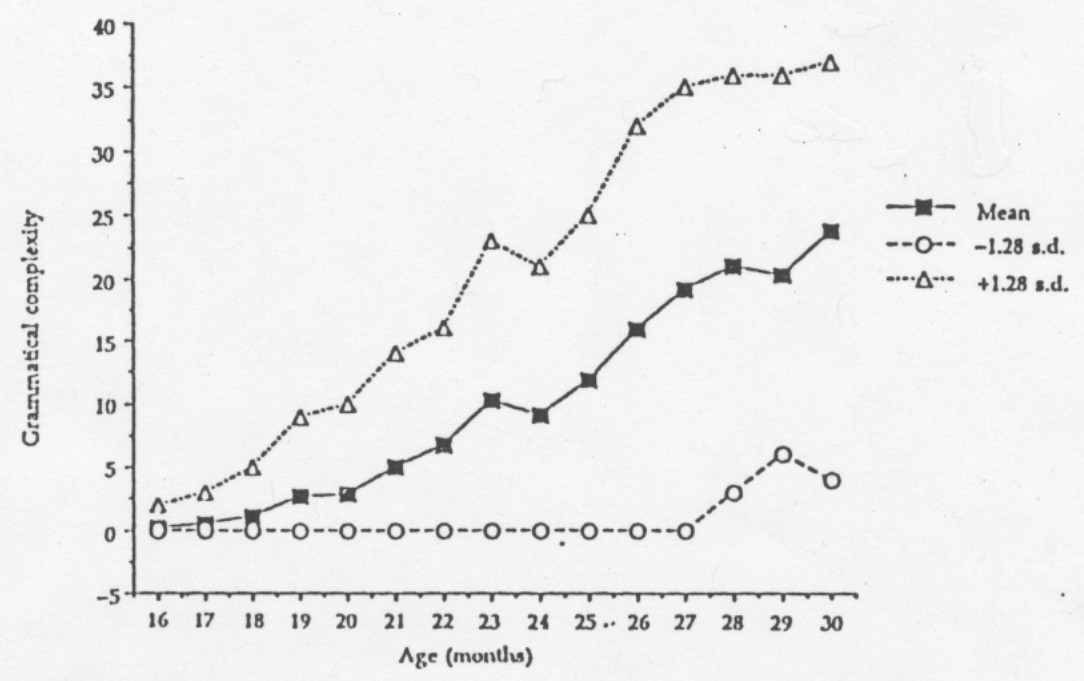

Figure 4.6 MacArthur CDI Toddler form estimaled MLU (observed).

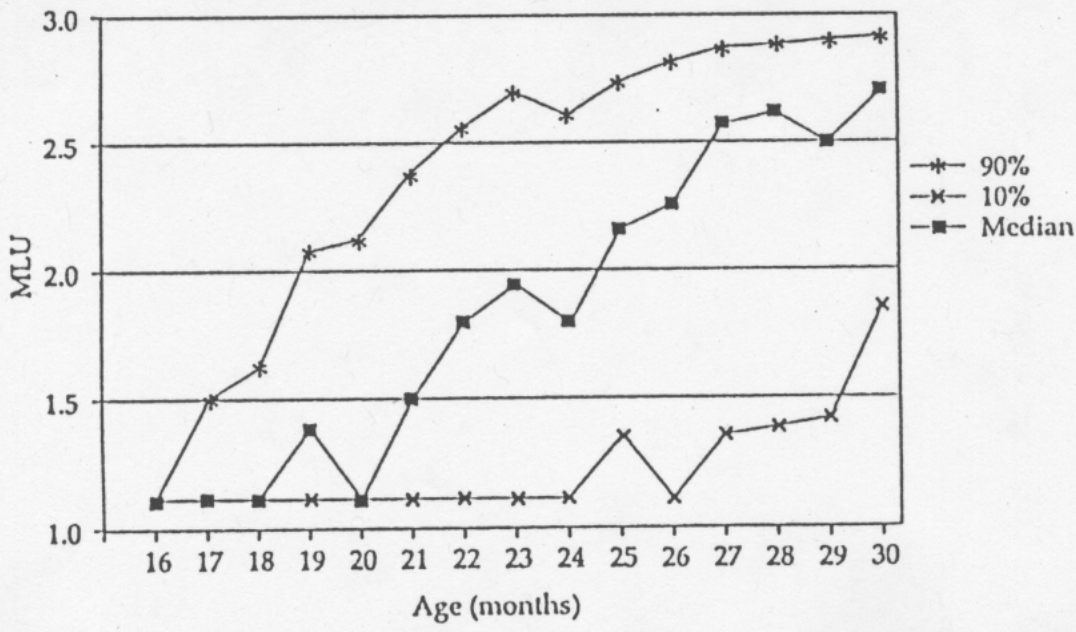


Figure 4.7 Number of words produced as a function of receptive vucabulary size on the MacArthur CDI Infant Scale.

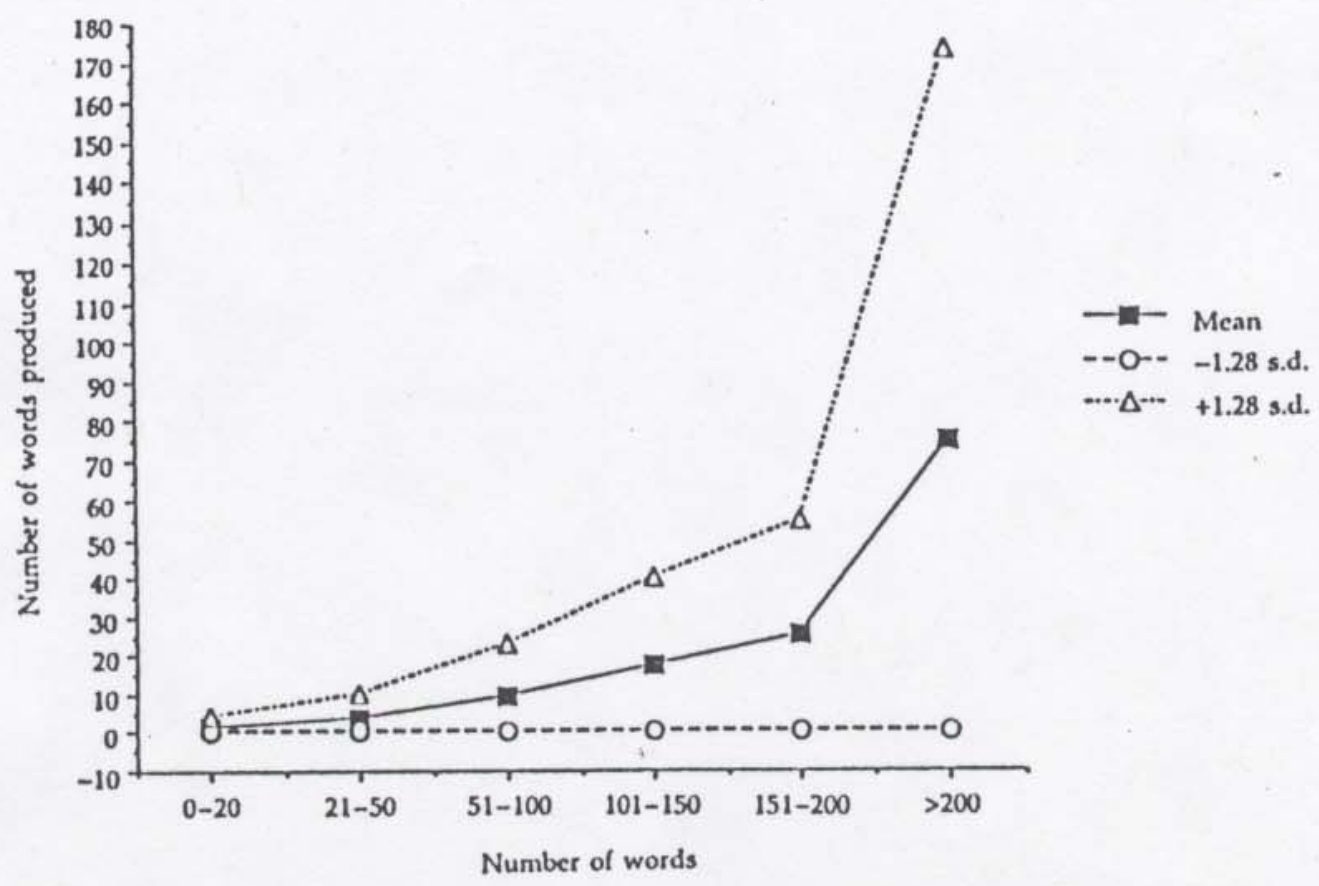

Figure 4.8 Vocabulary Composition as a function of vocabulary size on the MacArthur CDI Toddler Scale.

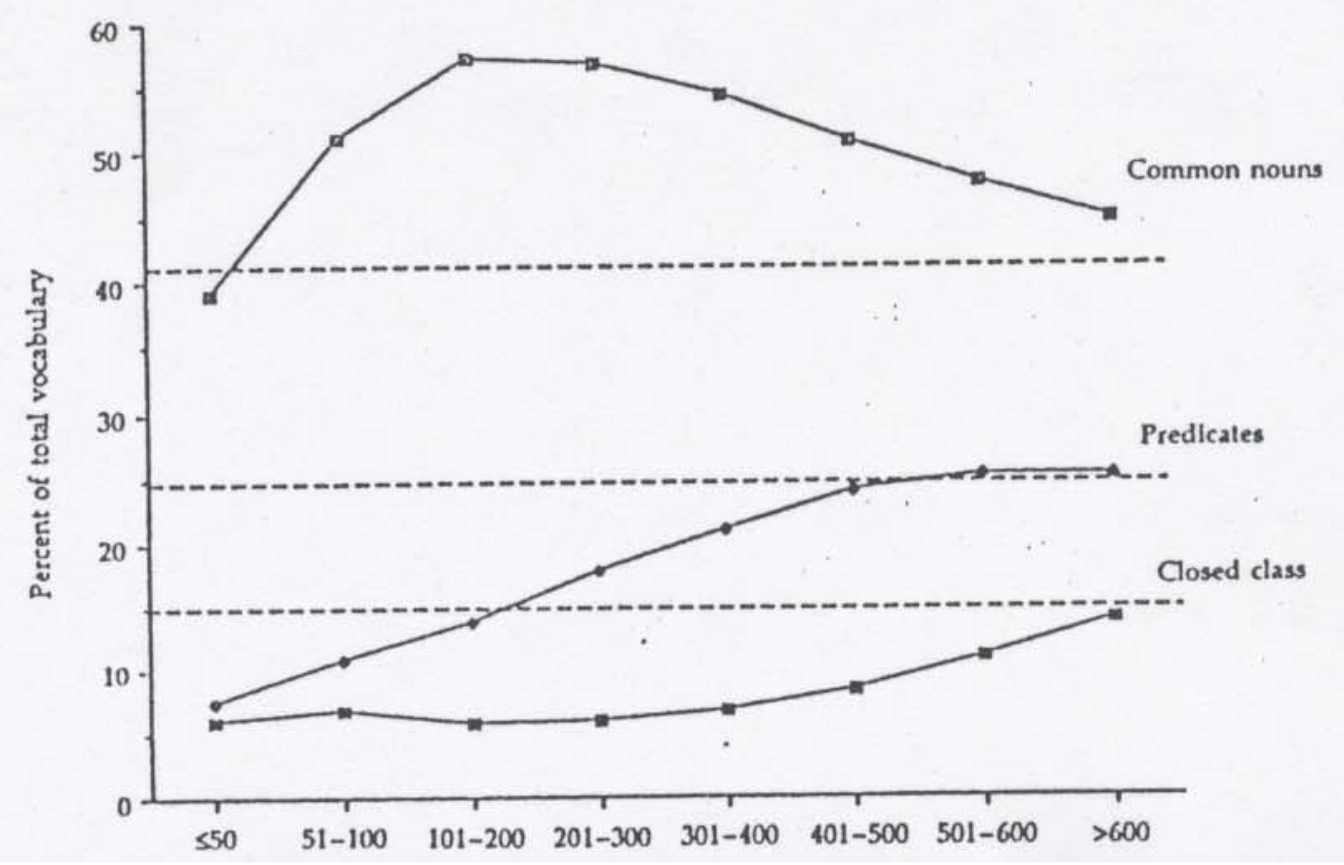


Figure 4.9 Percent of subjects producing word combinations as a function of vocabulary size on the MacArthur CDI Toddler Scale.

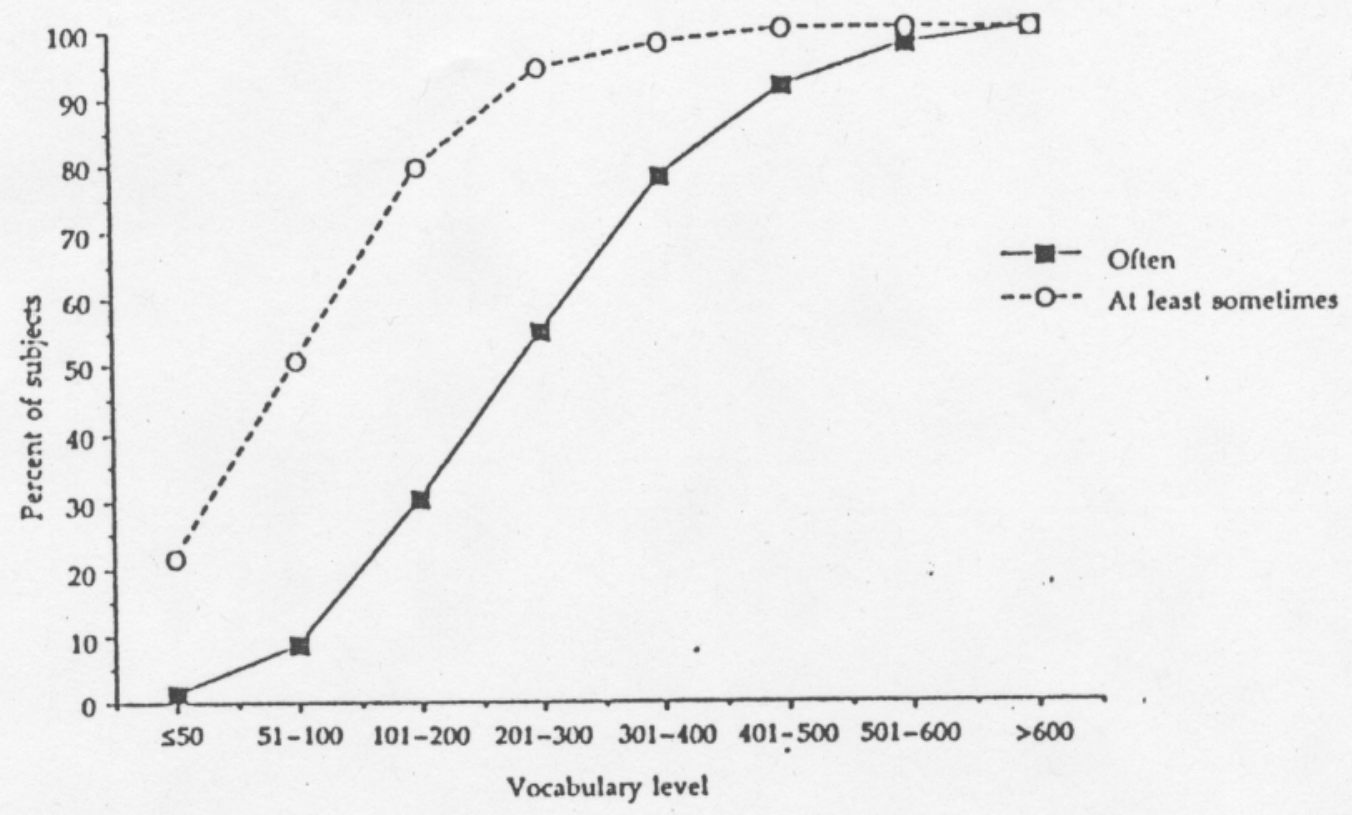

Figure 4.10 Grammatical complexity score as a function of vocabulary size on the Mac^rthur CDI Toddler Scale.

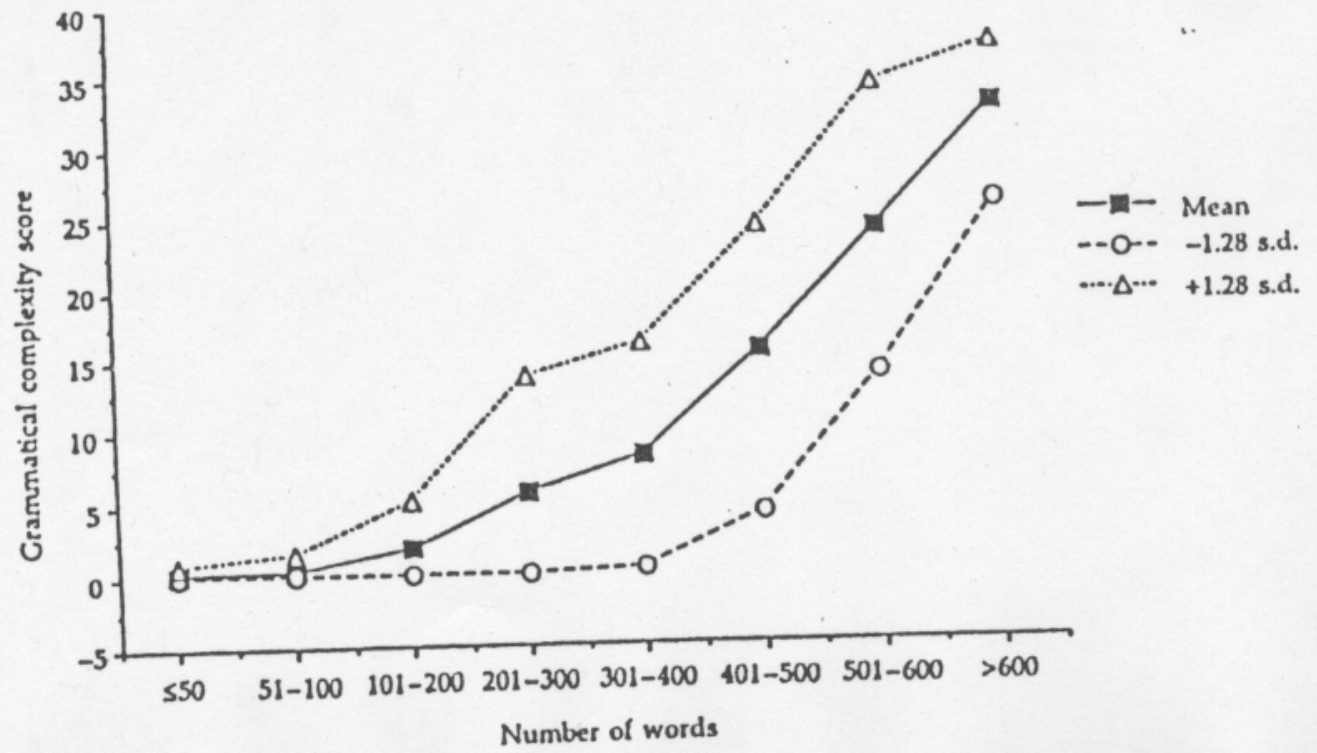


Figure 4.11 (a) Two-strand design: ideal patterns; (b) Pattern of best fit to the observed longitudinal data.

28 Months

20 Months

13 Months

$$
\begin{gathered}
\text { Strand } 1 \\
\text { comprehension / } \\
\text { analysis }
\end{gathered}
$$
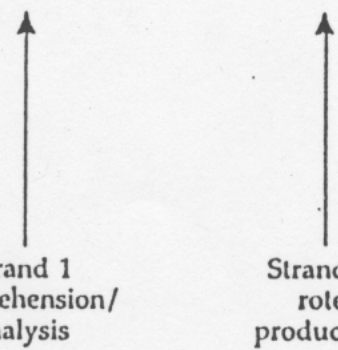

(a)

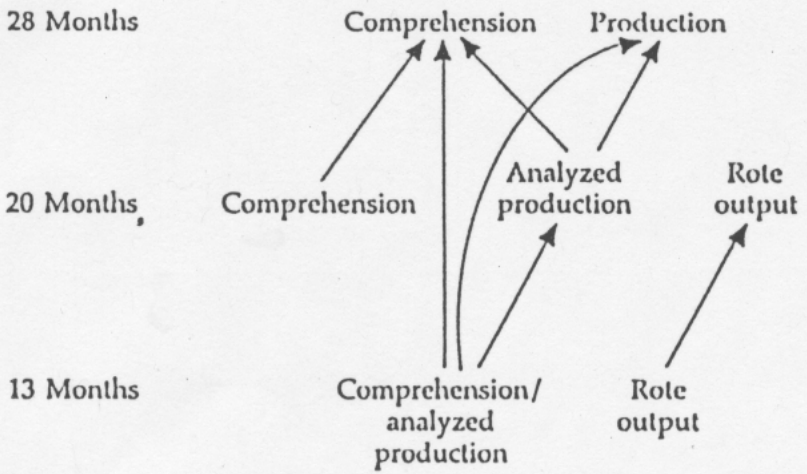

(b) 
Figure 4.12 Percent common nouns as a function of vocabulary size on the MacArthur CDI Toddler Scale.

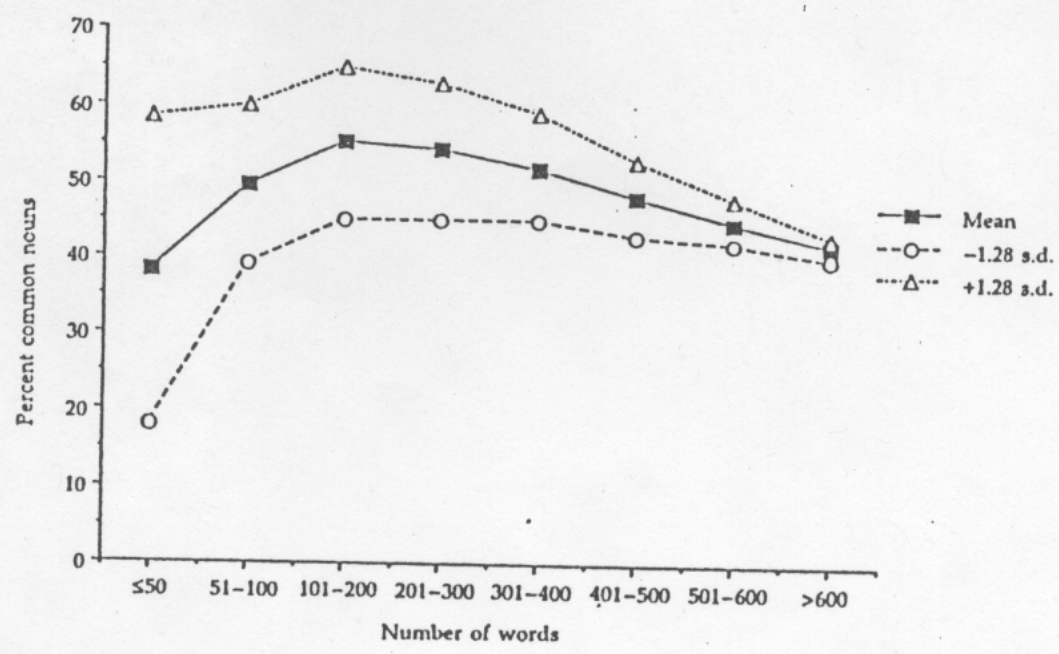

Figure 4.13 Percent closed class as a function of vocabulary size on the MacArthur CDI Toddler Scale.

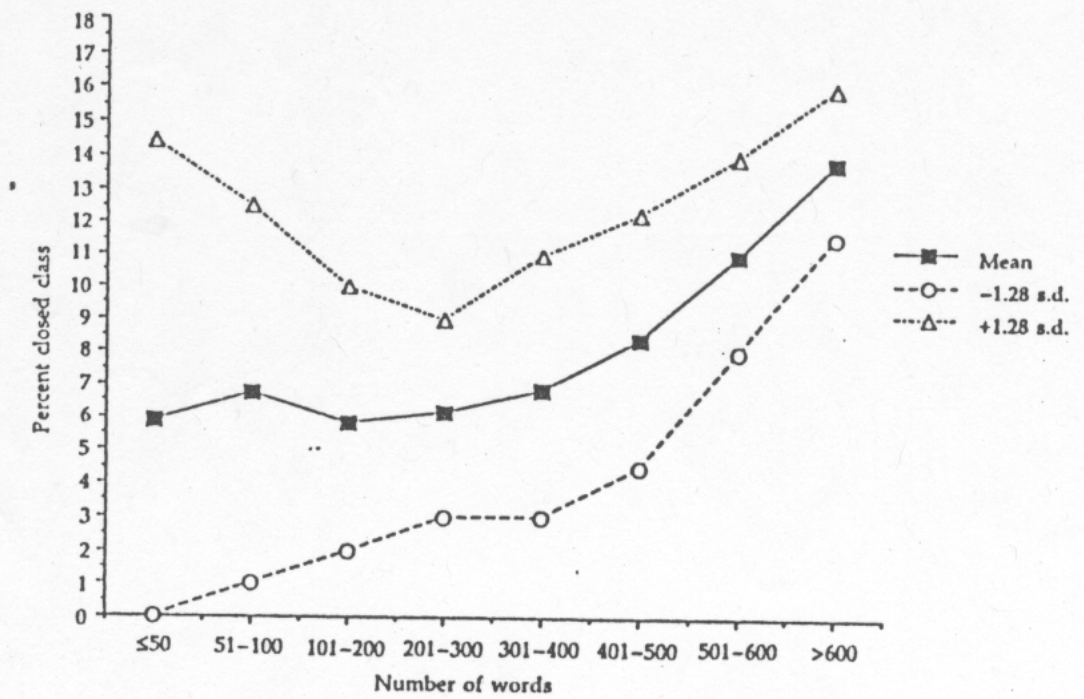

